\title{
Testing for Sex Differences in the Nomological Network of the Triarchic Model of Psychopathy in Incarcerated Individuals
}

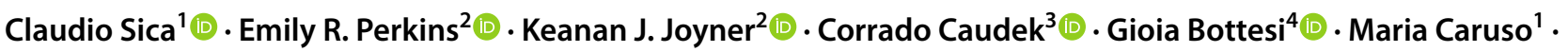 \\ Paolo Giulini ${ }^{1} \cdot$ Marta Ghisi ${ }^{4}\left(\right.$ D . Christopher J. Patrick ${ }^{2}$ (D)
}

Accepted: 12 May 2021 / Published online: 16 July 2021

(c) The Author(s) 2021

\begin{abstract}
The triarchic model of psychopathy conceptualizes variants of this clinical condition as expressions of three distinct biobehavioral dispositions, termed boldness, meanness, and disinhibition. As a trait-oriented model, the triarchic model situates psychopathy within a broader nomological network of personality and psychopathology, and has proven useful for characterizing how psychopathy relates to variables in these domains as well as to biological and behavioral variables. The current study was the first to examine sex differences in the external correlates of psychopathic traits as described by the triarchic model in a prison sample. Results were generally consistent with hypotheses: The triarchic traits related to measures of personality and psychopathology in patterns that were largely consistent across sex, but with some notable differences between males and females, in the correlates of disinhibition in particular. These included stronger associations for disinhibition with substance use problems, self-harm, and staff ratings of prison misbehavior among females compared to males. Findings from this study support the value of the triarchic model for understanding similarities and differences in the nomological network of psychopathy in incarcerated males and females.
\end{abstract}

Keywords Psychopathy $\cdot$ Triarchic model $\cdot$ Prison sample $\cdot$ Sex differences

Psychopathy is a personality disorder characterized by a constellation of interpersonal and affective traits (e.g., callousness, remorselessness, and superficial charm) coupled with impulsive and antisocial tendencies (Hare \& Neumann, 2008; Patrick, 2006). Although males appear more likely to present with psychopathy than females, the full syndrome of psychopathy does occur in both sexes. For instance, Hervey Cleckley, one

Claudio Sica

claudio.sica@unifi.it

$\square$ Emily R. Perkins

Perkins@psy.fsu.edu

1 Department of Health Sciences, Psychology Section, University of Firenze, Via San Salvi, 12, 50135 Firenze, Italy

2 Department of Psychology, Florida State University, 1107 W. Call Street, Tallahassee, Fl 32306-4301, USA

3 Department of Neurosciences, Drug Research, and Child Health, University of Firenze, Via San Salvi, 12, 50135 PsychologyFirenze, Italy

4 Department of General Psychology, University of Padova, via Venezia, 8, 35131 Padova, Italy of the founders of the modern conceptualization of psychopathy (1941), indicated that his female clients often exhibited many of the characteristics he had observed in his male clients (i.e., stealing, truancy, and pathological lying). However, several prominent scholars have proposed that psychopathy might be "expressed" differently in males and females: Just as developmental differences in cognitive and emotional development are likely to be reflected in the differential manifestation of psychopathic-like traits in children, gender-role socialization and biological differences might result in psychopathic traits being expressed differently in males and females (Cale \& Lilienfeld, 2002; Forouzan \& Cooke, 2005; Hamburger et al., 1996; Preston et al., 2018; Verona \& Vitale, 2018). In particular, some empirical studies have yielded evidence that psychopathy in females is more accompanied by internalizing symptomatology (e.g., depression, self-harm, suicidality) than in males (Blonigen et al., 2005; Sprague et al., 2012). However, further research is needed to test for sex differences in relations of psychopathy with distress-related conditions as well as with substance use and other externalizing problems (Schultz et al., 2016; Sellbom et al., 2017). Additionally, research is needed to evaluate whether psychopathic traits relate differently to 
adjustment within the prison setting and recidivism following release as a function of sex (Edens et al., 2007; Salekin et al., 1997; Stockdale et al., 2010).

The current study was undertaken to investigate sex differences in the external correlates of psychopathy, using the triarchic model of psychopathy (Patrick et al., 2009) as a frame of reference. Based on the existing conceptual and empirical literature, we formulated specific predictions regarding sex differences in the expression of distinct dispositional facets of psychopathy described by the triarchic model.

\section{Distinct Facets (Subdimensions) of Psychopathy}

Cleckley's (1941) description of psychopathy included both obviously maladaptive (e.g., pathological egocentricity, incapacity for love, lack of remorse, inadequately motivated antisocial behavior) and more adaptive traits (e.g., superficial charm, high intelligence, absence of delusions, absence of nervousness). Subsequent descriptions focused more specifically on the maladaptive traits such as exploitation, aggressiveness, and indifference to others (e.g., Karpman, 1948; McCord \& McCord, 1964).

Researchers have therefore disagreed on the core features of psychopathy. Some suggest that antisocial (including crime-related) behavior is intrinsic to psychopathy (Neumann et al., 2015), whereas others contend that such behavior is a consequence, or secondary symptom, of more basic psychopathic traits (Cooke et al., 2004). Additionally, whereas the role of seemingly adaptive characteristics (commonly referred to as fearless dominance or boldness) has been debated (e.g., Crego \& Widiger, 2016; Lilienfeld et al., 2012; Patrick et al., 2019), callous-exploitative tendencies appear to be emphasized in most models of psychopathy for both children and adults (Barry et al., 2000; Drislane et al., 2014; Lynam \& Derefinko, 2006; Verschuere et al., 2018).

As such, prominent models differ in their emphasis on particular aspects of psychopathy. For example, the Psychopathy Checklist - Revised (PCL-R; Hare, 2003), the most widely used measure of psychopathy, was developed as an assessment tool for psychopathy in prison settings. The PCL-R assesses psychopathy in terms of two broad dimensions: Factor 1, encompassing affective-interpersonal traits, and Factor 2, encapsulating the irresponsibility and crime-related features of psychopathy. The triarchic model of psychopathy (Patrick et al., 2009), in contrast, is a more recent conceptualization that uncouples crime from psychopathy and includes the potentially adaptive personality features that can lead to disparate outcomes (i.e., "criminal" versus "successful" psychopathy; Lilienfeld et al., 2018). Within the triarchic model, meanness encompasses deficient affective experience, social callousness, and lack of empathy; disinhibition is a proneness toward impulsive, unrestrained behavior; and boldness involves fearlessness, social dominance, and emotional resiliency. From the standpoint of the triarchic model, engagement in crime is considered a behavioral consequence of these psychopathic dispositions, rather than a core part of psychopathic personality itself. The triarchic model explicitly attempts to situate psychopathy as a set of dispositional traits within a broader nomological net of personality and psychopathology - that is, the network of linkages among hypothetical constructs and measures designed to quantify them (Cronbach \& Meehl, 1955).

\section{Participant Sex and Psychopathic Symptomatology}

Across theoretical models, psychopathy occurs in both sexes ${ }^{1}$ (Verona \& Vitale, 2018), although most clinical descriptions of psychopathy are based on its presentation in males, in whom the condition was initially observed. Perhaps as an artifact of this gendered description, males consistently score higher overall than females on most psychopathy assessments, including the PCL-R and related measures as well as operationalizations of the triarchic model. The difference appears primarily attributable to males' higher scores on the affective and interpersonal features, conceptualized in the PCL-R collectively as Factor 1 and in the triarchic model as meanness and boldness (Coid et al., 2009; Drislane \& Patrick, 2017; Falkenbach et al., 2017; Miller et al., 2008; Sica et al., 2015; c.f. Anestis et al., 2019). One possible explanation for this finding is that over the course of development, females may be socialized more so than males to adopt a warm, empathic, and collaborative affective-interpersonal approach (Eagly, 2009). This could result in lower scores on relevant facets of psychopathy - even adaptive attributes, such as leadership ability, that are reflected in boldness scores (see Preston et al., 2018). However, some studies with undergraduate samples have found that all facets of PCL-R-aligned psychopathy i.e., including Factor 2 as well as Factor 1 - are elevated among males (Forth et al., 1996; Lilienfeld \& Hess, 2001; Wilson et al., 1999). The finding that males score higher than females on PCL-R Factor 2, but not generally on triarchic

\footnotetext{
${ }^{1}$ For the purposes of these analyses, given the limitations of available data, we explore differences in the nomological net of psychopathy related to biological sex and not gender identity/expression. We also treat biological sex as a binary variable based on available data, despite evidence for substantial variability in both biological sex and gender identity/expression (Hyde et al., 2019). However, we strongly encourage further research on the full spectra of biological sex and gender identity/expression in relation to psychopathy and other psychological topics (Cameron \& Stinson, 2019).
} 
disinhibition, could reflect the inclusion of crime-related behaviors more common in men in the criteria for Factor 2 (Bolt et al., 2004; Moffitt et al., 2001). It may be that the underlying predisposition to impulsive behavior (i.e., disinhibition) is similar across sexes, but its manifestation as crimerelated behavior (represented in Factor 2) is more common in males.

\section{External Validity of Psychopathy in Males and Females}

One critical task in understanding the role of sex in psychopathy is to situate the facets of psychopathy within a nomological network (Cronbach \& Meehl, 1955), thus elucidating how psychopathy coheres with external personality and psychopathology measures in males versus females. Several studies have examined the associations of psychopathy facets with criterion measures of personality in both sexes, largely finding parallel patterns of correlations with common measures of personality for males and females using both PCL-R-derived and triarchic-based measures. For example, studies of the five-factor model (FFM) of personality have found almost identical patterns of association with various measures of Factor 1 and Factor 2 in male and female undergraduates (Derefinko \& Lynam, 2006; Miller et al., 2008, 2011). In addition, the triarchic facets correlate with most FFM traits to similar degrees in male and female undergraduates. The exception is agreeableness, which demonstrates a stronger negative correlation with meanness - and, to a lesser extent, boldness - in males than females (Poy et al., 2014; Sica et al., 2015). High meanness in females may therefore reflect other aspects of this trait besides overt antagonism (low agreeableness), such as estrangement from others (alienation) or maladaptive emotionality. Again, this finding could be attributable to gender role socialization and societal expectations that women be interpersonally pleasant (Eagly, 2009), leading the trait of meanness in females to contain a greater proportion of variance related to nonantagonistic components of social-affective behavior. Overall, psychopathy appears similarly positioned in relation to personality in males and females, according to measures based on both the PCL-R and the triarchic model.

With regard to psychopathology, most externalizing problems are correlated with psychopathy to similar degrees across sexes. For example, although males may evidence a higher mean rate of engagement in crime than females (Moffitt et al., 2001), the degree of covariation between aggressive behavior and psychopathy is similar across sexes (e.g., Preston et al., 2018). In addition, studies with measures derived from the PCL-R show similar associations with alcohol use, substance use, and antisocial behavior in male and female undergraduates (Forth et al., 1996; Miller et al., 2011; Sellbom et al., 2017). Only two studies to date examined sex as a moderator of correlations between triarchic facets of psychopathy and antisocial behavior. One found no significant sex differences in a community sample (Fanti et al., 2016). The other, using a sample of individuals undergoing a forensic mental health evaluation, found no sex differences in the association between psychopathic traits and substance use problems, but higher correlations between meanness, disinhibition, and history of engagement in crime among females than males (Anestis et al., 2019). Direct comparisons between males and females using triarchic measures and unselected prison samples are still lacking; more research is needed to understand how psychopathy is situated within the nomological net of externalizing problems.

More complex patterns of external correlates for male versus female psychopathy emerge in relation to internalizing psychopathology. For example, in community samples, associations with fear- and anxiety-related criteria appear fairly consistent across sexes (Fanti et al., 2016; Sica et al., 2015). However, depression and affiliated distress conditions show some sex differences in relation to psychopathy. For example, psychopathy is more closely linked to borderline personality disorder symptoms in females than males (Sprague et al., 2012). In addition, in an undergraduate study using measures derived from the PCL-R, although Factor 2 was positively associated with non-suicidal self-injury (NSSI) in both sexes, Factor 1 showed an additional positive correlation with NSSI in females only (Miller et al., 2011). Among incarcerated juveniles, Sevecke et al. (2009) reported that the affective symptom facet of Factor 1 was associated with reduced anxious-depressive symptoms among males, but increased suicidality among females. These authors also found both symptom facets of Factor 2 - impulsive lifestyle and antisocial behavior - to be positively associated with suicidality among incarcerated juvenile females only. Finally, callous-unemotional traits have been linked to greater internalizing problems in community girls, but not boys (Essau et al., 2006). Taken together, these findings suggest that Factor 1, and particularly the affective (i.e., callousunemotional) features of psychopathy, may relate to distress-related phenomena in opposing directions for males and females. One possibility is that among females, higher scores on the affective features of psychopathy, as assessed by the PCL-R and related measures, may reflect emotional numbing/dysregulation and anhedonia typical of depression and suicidality rather than callous unemotionality. This would be consistent with the foregoing hypothesis that meanness and agreeableness are less correlated in females because meanness reflects alienation and emotional dysfunction more so than antagonism in females. In contrast, for males, the same affective items may capture reduced vulnerability to distress, an adaptive trait. 
Most prior research has utilized PCL-R and related measures, which largely exclude adaptive features from the construct of psychopathy, perhaps contributing to the unclear picture of sex differences in relations between psychopathy and internalizing problems. By providing better representation of such adaptive features (i.e., boldness), the triarchic model is well positioned to clarify sex differences in the relationship between psychopathy and distress-related psychopathology (Latzman et al., 2019). One of two studies of this kind published to date (Sica et al., 2015), using a community sample, presented evidence that meanness was not associated with depression in either sex, whereas boldness was negatively correlated with depression in both sexes and disinhibition was positively associated with depression and stress in females only. It is possible that although average levels of disinhibition are similar across sexes, the proportion of negative affectivity- to impulsivity-related variance in disinhibition scores is higher among females, leading to a higher correlation with these internalizing symptoms. However, among individuals referred for a forensic mental health evaluation, only boldness was associated with depression, and sex did not moderate any depression effects (Anestis et al., 2019). These results require clarification as well as extension to correctional samples to better understand how distinct aspects of psychopathy may relate in opposing directions to risk for internalizing problems.

A final topic of interest in the examination of sex differences in psychopathy's nomological net regards behavior in legal contexts. Psychopathy is frequently used in forensic psychology as a prognostic indicator for adjustment within the prison setting and likelihood of recidivism following release (Walters, 2003). However, sex differences in the utility of psychopathy measures in risk assessment have not been examined in depth. One prior mixed-sex study suggests that both PCL-R Factor 1 and Factor 2 were associated with recidivism in incarcerated females, whereas only Factor 2 predicted recidivism in incarcerated males (Coid et al., 2009). Again, some have questioned the relevance to females of specific forms of crime included in the criteria for PCL-R Factor 2 (e.g., Strand \& Belfrage, 2005; Verona \& Vitale, 2018). Nonetheless, this finding remains to be replicated and examined in a way that averts criterion contamination related to history of engagement in crime. The triarchic model's characterization of psychopathy in traitdispositional terms offers a useful complement to formulations of psychopathy derived from forensic research, in which males have comprised the vast majority of participants. In addition, other measures of behavior during incarceration require examination in relation to male and female psychopathy.

\section{The Current Study}

Given the abovementioned gaps in the literature, the current study attempted to provide further insight into sex differences in the external correlates of psychopathy through reference to the triarchic model in an incarcerated sample. Based on the prior research discussed above, major study hypotheses were as follows:

1. We sought to extend prior community-sample findings regarding psychopathy and the FFM (Poy et al., 2014; Sica et al., 2015) to incarcerated individuals, hypothesizing that triarchic traits would relate to the FFM largely similarly across sex, but that meanness would be correlated to a greater degree with low agreeableness (i.e., antagonism) in males than females. Apart from this, we expected that in both sexes, and to similar degrees, boldness would be associated negatively with FFM neuroticism and positively with extraversion and openness; meanness would be negatively with associated with both extraversion and openness; and disinhibition would be associated negatively with conscientiousness and positively with neuroticism.

2. Drawing on prior research (Anestis et al., 2019; Brislin et al., 2015; Gottfried et al., 2019; Miller et al., 2011; Sellbom et al., 2018), we hypothesized that disinhibition, and to a lesser extent meanness, would be positively associated with substance use problems across sex.

3. Based on prior research on psychopathy and internalizing among undergraduates, forensic samples, and incarcerated juveniles (Anestis et al., 2019; Miller et al., 2011; Sevecke et al., 2009; Sica et al., 2015), we hypothesized that disinhibition would predict hopelessness more so in females than in males, and that meanness would predict hopelessness and NSSI positively in females but negatively in males. In addition, we predicted negative associations for boldness with distressrelated symptomatology in both sexes.

4. Given prior evidence for sex differences in the utility of PCL-R Factor 2 in forensic contexts (Coid et al., 2009), we tentatively hypothesized that disinhibition would be associated with lower staff ratings of general prison behavior, social connectedness, and reintegration prognosis to a greater degree in males than females.

\section{Method}

\section{Participants}

Study participants were 277 male and 85 female inmates from 10 different medium- and high-security prisons in Northern and Central Italy (seven male facilities, three female facilities). Prisons were selected to be representative of Italian correctional facilities, and residents of these facilities were from various geographic areas of the 
country. Individuals who had been convicted of severe crimes and/or financial and fraud-related crimes (versus less serious property crimes or minor drug offenses), as determined from a review of prison files, were considered for enrollment in the study. Exclusion criteria were (1) current diagnosis of major mental illness (e.g., schizophrenia, Bipolar I) or intellectual disability, (2) involvement with the institution's Drug Addiction Services over the last six months (i.e., requiring pharmacological treatment such as methadone to mitigate withdrawal and craving symptoms from severe substance use disorder), (3) lack of fluency in the Italian language, (4) visual or hearing impairments, and (5) an imminent date of release from the prison. The first of these five characteristics was determined from the Psychiatric Services files of each institution; the remaining four were determined from centralized prison records.

Eligible individuals were invited to participate in the study through their institutional case managers. Participation was completely voluntary, with no direct incentives for participating or consequences for declining to participate. Of those eligible, the enrollment rate was approximately $95 \%$, with no substantial differences across the 10 prison facilities.

Four male and two female participants were excluded from analyses due to incomplete questionnaire data, yielding a final analysis sample of 273 male and 83 female inmates, all of whom were Caucasian. Males were modestly older than females but did not differ in years of education (see Table 1; other demographic data as well as information about convictions and sentencing are in Supplementary Material).

\section{Measures}

\section{Triarchic Psychopathy Measure (TriPM; Patrick, 2010)}

The Italian-language translation of the 58-item TriPM was used to operationalize Boldness, Meanness, and Disinhibition subscales. Participants responded on a four-point Likert scale $(0=$ false, $1=$ somewhat false, $2=$ somewhat true, $3=$ true). The TriPM Disinhibition and Meanness subscales (20 and 19 items, respectively) consist of items that index the general externalizing factor and callous-aggression subfactor, respectively, of the externalizing spectrum model (Krueger et al., 2007). The 19-item Boldness scale indexes the general factor from a multi-scale measure of fearless-dominant tendencies (Patrick et al., 2019).

Consistent with prior work reporting good internal consistencies in both prison and community samples (e.g., Sellbom $\&$ Phillips, 2013), and in Italian community individuals (Sica et al., 2015), Cronbach's alphas in the current study sample were .75 for Boldness (males=.70; females=.76), .85 for Meanness (males=.84; females=.81), and .87 for Disinhibition (males=.84; females $=.87$ ). Published research has demonstrated convergent and discriminant validity for the TriPM scales in relation to a wide array of criterion measures, including other commonly used psychopathy measures (e.g., Drislane et al., 2014; Sellbom \& Phillips, 2013; Sica et al., 2015; Venables et al., 2014).

\section{NEO Five-Factor Inventory (NEO-FFI; Costa \& McCrae, 1992)}

The NEO-FFI comprises 60 items selected on the basis of factor loadings from the 240-item Revised NEO Personality Inventory domains: Neuroticism, Extraversion, Openness, Agreeableness, and Conscientiousness. Participants indicated their level of agreement with each item on a five-point Likert scale $(1=$ strongly disagree to $5=$ strongly agree). The Italian NEO-FFI has demonstrated good reliability and validity in previously published research (e.g., Sica et al., 2015). For the current study, Cronbach's alphas were .75 for Neuroticism (males $=.72$; females $=.75$ ), .70 for Extraversion (males=.65; females=.63), .55 for Openness (males $=.54$; females $=.53$ ), .58 for Agreeableness (males $=.55$; females $=.61$ ), and .77 for Conscientiousness (males $=.75$; females $=.80$ ).

\section{Externalizing Spectrum Inventory - Brief Form (ESI-bf; Patrick et al., 2013a, b)}

The ESI-bf Substance Abuse scale contains items assessing simple use of various substances and well as problems related to substance use. Given the ubiquity of substance use in correctional samples, a subset of nine ESI-bf Substance Abuse items indexing problematic use was employed in the current analyses (i.e., a Substance Use Problems scale; ESIbf-SUP). The nine items included three each pertaining to problems with alcohol (e.g., "I've had to drink more than I used to in order to get the same buzz"), marijuana (e.g., "I've had urges to use marijuana that were hard to resist"), and other substances (e.g., "At some point in my life, I couldn't get high from a drug dose that worked before"). Participants responded on a four-point Likert scale $(0=$ false, $1=$ somewhat false, $2=$ somewhat true, $3=$ true). Cronbach's alpha in this sample for the total score was .85 (males $=.83$, females=.90).

\section{Beck Hopelessness Scale (BHS; Beck \& Steer, 1993)}

The BHS assesses three major aspects of hopelessness: feelings about the future (e.g., "In the future I expect to succeed in what concerns me most" [reverse-coded]), loss of motivation ("I might as well give up because there's nothing I can do to make things better for myself"), and negative expectations ("Things just won't work out the way I want them to"). Participants indicated whether each of 20 statements 
accurately characterized their psychological state over the last week $(0=$ false, $1=$ true $)$. The BHS has been widely used in research on depression and suicide (Beck \& Steer, 1993). The Italian version of this measure has shown good reliability and validity in a variety of studies (e.g., Pompili et al., 2009). Cronbach's alpha in the current study sample was .86 for the total score $($ males $=.88$; females $=.83$ ).

\section{Deliberate Self-Harm Inventory (DSHI; Gratz, 2001)}

The 17-item DSHI defines deliberate self-harm as intentionally inflicted bodily injury not involving conscious suicidal intent but severe enough to cause tissue damage. The DSHI lists 17 different types of deliberate self-harm (e.g., cutting, burning with lighter or match, etc.) and for each of them assesses various aspects, including frequency and duration. Specifically, the DSHI asks participants whether and how often they have engaged in a variety of behaviors "intentionally" (i.e., on purpose). It yields scores reflecting the frequency (i.e., total instances of engagement in self-harmful behavior) and versatility of self-harm behavior (i.e., number of different types of self-harmful behavior). Within the current sample, $17 \%$ of participants reported at least four selfharm attempts or one attempt severe enough that it required medical assistance. A log transformation was performed on the DSHI frequency scores in order to reduce the impact of extreme values; these log-transformed frequency scores correlated quite highly (.82) with scores on the versatility variable. The original version and Italian translation of this measure have been shown to be a reliable and valid index of self-harm behavior (Cerutti et al., 2011; Fliege et al., 2006; Gratz, 2001).

\section{Staff Ratings}

For each participant, a case manager rated the following characteristics: (a) behavior in prison $(1=$ very bad to $5=$ very good; $N=264$ males and 83 females); (b) presence of social connections with relatives and/or friends ( $1=$ none, isolated to $5=$ important and stable social links outside prison; $N=264$ males and 82 females); and (c) reintegration prognosis $(1=$ negative, many failures in the past to $5=$ positive and favorable; $N=242$ males and 73 females). These ratings were formulated by each case manager on the basis of multiple sources of data: the participant's prison file, the frequency and quality of social contacts (including letters, phone calls, visits, etc.), direct interactions (including case-related interviews) with the participant, behavior of the participant during periods of occasional release (e.g., funeral attendance), and reports about the participant filed by prison correctional staff.

\section{Procedure}

Authorization to collect data from the 10 prisons was obtained from the National Administration of Prisons (Dipartimento dell'Amministrazione Penitenziara; DAP) and its local branches for the northern Italian region of Lombardy and central Italian region of Tuscany. Procedures for the study complied fully with the provisions of the Declaration of Helsinki and were approved by the Institutional Review Board of the University of Firenze as well as by the DAP. All participants provided informed written consent prior to participation in the study. Participants completed the above-noted self-report questionnaires in small groups. Questionnaire administration order was varied to control for order effects.

\section{Data Analysis}

To accommodate cases with partial missing data, maximum likelihood estimates were computed using an expectationmaximization algorithm. Pearson's correlations $(r s)$ were first calculated for each TriPM scale with each criterion variable. Following Cohen's (1988) classification, large correlations were defined as .50 and above, medium correlations between .30 and .49 , and small correlations between .10 and .29 . To test for differences of correlations across sex, Fisher's $r$ to $z$ transformation was utilized. Multiple regression was used for all subsequent analyses to test for unique relations between TriPM scales and criterion variables, as well as to test for moderation of these associations by sex. For each outcome variable ( $z$-scored), participant sex $(0=$ male, $1=$ female $)$ was entered at Step $1, z$-scores for the three TriPM scales were entered at step 2, and Sex x TriPM-scale interaction terms were entered together at Step 3. The incremental contributions of the interaction terms were evaluated by testing whether their inclusion at Step 3 accounted for significant additional variance in the outcome measure (i.e., $\Delta R^{2} p<.05$ ). Significant interaction terms were explored using the emtrends function of the emmeans package (Lenth, 2021) in the R statistical environment (version 4.0.4; R Core Team, 2021).

\section{Results}

\section{Descriptive Statistics for Male and Female Subsamples}

Table 1 shows descriptive statistics for all study variables by participant sex, along with statistics pertaining to sex differences in mean scores. Females had slightly higher mean scores than males on disinhibition (Cohen's $\eta^{2}=.02$ ), other 
Table 1 Descriptive statistics

\begin{tabular}{|c|c|c|c|c|c|c|c|c|c|c|}
\hline \multirow[b]{2}{*}{ Study variable } & \multicolumn{4}{|l|}{ Males } & \multicolumn{4}{|c|}{ Females } & \multirow[b]{2}{*}{$F$} & \multirow[b]{2}{*}{$\eta^{2}$} \\
\hline & $M$ & $S D$ & $\alpha$ & $r$ & $M$ & $S D$ & $\alpha$ & $r$ & & \\
\hline \multicolumn{11}{|l|}{ Demographics } \\
\hline Age (years) & 47.2 & 12.7 & -- & -- & 42.1 & 11.9 & -- & -- & $10.4^{* *}$ & .03 \\
\hline Education (years) & 9.5 & 3.6 & -- & -- & 9.2 & 3.2 & -- & -- & 0.3 & .00 \\
\hline \multicolumn{11}{|c|}{ Triarchic Psychopathy Measure (TriPM) } \\
\hline Total & 120.4 & 20.5 & .87 & .31 & 123 & 22.8 & .89 & .32 & 0.9 & .00 \\
\hline Boldness & 47 & 7.3 & .70 & .27 & 45.5 & 9.1 & .76 & .34 & 2.2 & .00 \\
\hline Meanness & 31.8 & 10.0 & .84 & .49 & 32.3 & 8.6 & .81 & .38 & 0.2 & .00 \\
\hline Disinhibition & 41.6 & 11.0 & .84 & .41 & 45.0 & 12.2 & .87 & .46 & $5.8^{*}$ & .02 \\
\hline \multicolumn{11}{|l|}{ Beck Hopelessness Scale (BHS) } \\
\hline Total & 4.9 & 4.2 & .88 & .51 & 5.4 & 3.9 & .83 & .42 & 1.0 & .00 \\
\hline Feeling about the future & 2.4 & 1.5 & .76 & .37 & 2.6 & 1.4 & .75 & .49 & 1.5 & .00 \\
\hline Loss of motivation & 1.4 & 1.9 & .78 & .52 & 1.8 & 1.8 & .71 & .40 & 2.3 & .00 \\
\hline Negative expectations & 1.1 & 1.5 & .63 & .37 & 1.0 & 1.5 & .58 & .33 & 0.2 & .00 \\
\hline \multicolumn{11}{|c|}{ Externalizing Spectrum Inventory (ESI) } \\
\hline Total substance use problems & 2.0 & 2.1 & .83 & .54 & 2.4 & 2.8 & .90 & .66 & 2.1 & .00 \\
\hline Alcohol problems & .93 & .88 & .67 & .49 & .94 & 1.0 & .71 & .53 & 0.9 & .00 \\
\hline Marijuana problems & .59 & .91 & .76 & .59 & .71 & 1.0 & .75 & .59 & 1.1 & .00 \\
\hline Other drug problems & .47 & .80 & .68 & .50 & .72 & 1.2 & .85 & .73 & $5.3^{*}$ & .01 \\
\hline \multicolumn{11}{|c|}{ Deliberate Self-Harm Inventory (DSHI) } \\
\hline Frequency (log-transformed) & .5 & 1.0 & -- & -- & 1.2 & 1.7 & -- & -- & $19.8^{* *}$ & .05 \\
\hline Versatility & .66 & 1.3 & -- & -- & 1.3 & 1.9 & -- & -- & $12.0^{* *}$ & .04 \\
\hline \multicolumn{11}{|l|}{ NEO Five-Factor Inventory } \\
\hline Neuroticism & 19.3 & 7.8 & .72 & .36 & 25.4 & 9.1 & .75 & .41 & $36.6^{* *}$ & .09 \\
\hline Extraversion & 29.2 & 6.8 & .65 & .34 & 28.2 & 6.6 & 63 & .27 & 1.3 & .00 \\
\hline Openness & 27.8 & 6.1 & .54 & .20 & 28.2 & 6.5 & .53 & .20 & 0.4 & .00 \\
\hline Agreeableness & 29.1 & 6.1 & .55 & .22 & 26.4 & 6.9 & .61 & .24 & $11.3^{* *}$ & .03 \\
\hline Conscientiousness & 35.8 & 6.9 & .75 & .40 & 35.4 & 7.9 & .80 & .47 & 0.2 & .00 \\
\hline \multicolumn{11}{|l|}{ Staff ratings } \\
\hline Social connections & 4.0 & 1.1 & -- & -- & 3.9 & 1.1 & -- & -- & .03 & .00 \\
\hline Behavior in prison & 4.0 & .08 & -- & -- & 3.7 & 1.0 & -- & -- & $4.9^{*}$ & .01 \\
\hline Reintegration prognosis & 3.7 & 1.0 & -- & -- & 3.6 & 1.1 & -- & -- & 0.7 & .00 \\
\hline
\end{tabular}

Total $N=356$; male $n=273$; female $n=83 ; r=$ mean item-total correlations. Cohen's $\eta^{2} \geq .01$ is small; $\geq .06$ is moderate; $\geq .14$ is large (Cohen, 1988). Staff ratings: range $=1$ to 5 , with higher scores indicating more positive evaluations

${ }^{*} p<.05 ;{ }^{* *} p<.01$

drug problems (non-alcohol, non-marijuana; $\eta^{2}=.01$ ), and frequency and versatility of self-harm $\left(\eta^{2} s=.05\right.$ and .04$)$, as well as moderately higher neuroticism scores $\left(\eta^{2}=.09\right)$. Males scored slightly higher on agreeableness $\left(\eta^{2}=.03\right)$ and staff ratings of prison behavior $\left(\eta^{2}=.01\right)$.

\section{First-Order Associations of Sex and TriPM Scales with Criterion Variables}

Table 2 displays results from the first and second steps of three-step hierarchical regression models for the full study sample; participant sex was entered at Step 1 and each TriPM scale was added at Step 2 to predict each criterion measure. ${ }^{2}$ First-order effects of sex at Step 1 mirrored the mean differences reported above. At Step 2, various firstorder effects were observed for the TriPM scales, controlling for sex and the other triarchic traits. Specifically, TriPM Boldness showed unique negative associations with the BHS total score and all subscales, NEO-FFI Neuroticism, and staff-rated prison behavior and reintegration prognosis, as

\footnotetext{
${ }^{2}$ In the Supplementary Material, we also report bivariate $r$ s for the three TriPM scales with each criterion measure, overall and separately for males and female participants, along with Fisher's $z$ tests of sex differences in the observed $r$ s.
} 
Table 2 Steps 1 and 2 of hierarchical regression models predicting each criterion variable

\begin{tabular}{|c|c|c|c|c|c|}
\hline \multirow[b]{2}{*}{ Study variable } & \multirow{2}{*}{$\begin{array}{l}\text { Step } 1 \\
\text { Sex } \\
B\end{array}$} & \multicolumn{3}{|l|}{ Step 2} & \multirow[b]{2}{*}{$\begin{array}{l}\text { Step } 2 \\
\text { Multiple } R \\
\left(\Delta R^{2}\right)\end{array}$} \\
\hline & & $\begin{array}{l}\text { Boldness } \\
B\end{array}$ & $\begin{array}{l}\text { Meanness } \\
B\end{array}$ & $\begin{array}{l}\text { Disinhibition } \\
B\end{array}$ & \\
\hline \multicolumn{6}{|l|}{ Beck Hopelessness Scale (BHS) } \\
\hline Total & .12 & $-.30^{* *}$ & $.25^{* *}$ & $.12^{*}$ & $.40\left(.16^{* *}\right)$ \\
\hline Feeling about the future & -.05 & $-.21^{* *}$ & $.23^{* *}$ & .04 & $.30\left(.09^{* *}\right)$ \\
\hline Loss of motivation & .19 & $-.26^{* *}$ & $.23^{* *}$ & .08 & $.35\left(.12^{* *}\right)$ \\
\hline Negative expectations & .16 & $-.28^{* *}$ & $.16^{* *}$ & $.20^{* *}$ & $.39\left(.15^{* *}\right)$ \\
\hline \multicolumn{6}{|c|}{ Externalizing Spectrum Inventory (ESI) } \\
\hline Total substance use problems & .18 & $.10^{*}$ & .01 & $.55^{* *}$ & $.57\left(.32^{* *}\right)$ \\
\hline Alcohol use problems & .04 & .09 & .01 & $.42^{* *}$ & $.44\left(.19^{* *}\right)$ \\
\hline Marijuana use problems & .13 & .07 & .00 & $.45^{* *}$ & $.46\left(.20^{* *}\right)$ \\
\hline Other drug use problems & $.29^{*}$ & $.10^{*}$ & .01 & $.50^{* *}$ & $.54\left(.27^{* *}\right)$ \\
\hline \multicolumn{6}{|c|}{ Deliberate Self-Harm Inventory (DSHI) } \\
\hline Frequency (log-transformed) & $.54^{* *}$ & -.06 & .08 & $.32^{* *}$ & $.43\left(.14^{* *}\right)$ \\
\hline Versatility & $.49^{* *}$ & -.05 & -.01 & $.31^{* *}$ & $.37\left(.09^{* *}\right)$ \\
\hline \multicolumn{6}{|l|}{ NEO Five-Factor Inventory } \\
\hline Neuroticism & $.72^{* *}$ & $-.39^{* * *}$ & .09 & $.34^{* *}$ & $.61\left(.28^{* *}\right)$ \\
\hline Extraversion & -.14 & $.40^{* *}$ & $-.19^{* *}$ & .01 & $.40\left(.16^{* *}\right)$ \\
\hline Openness & .08 & $.19^{* * *}$ & $-.29^{* *}$ & -.02 & $.33\left(.11^{* *}\right)$ \\
\hline Agreeableness & $-.41^{* *}$ & -.04 & $-.40^{* *}$ & $-.20^{* *}$ & $.57\left(.30^{* *}\right)$ \\
\hline Conscientiousness & -.05 & $.21^{* *}$ & $-.26^{* *}$ & $-.28^{* *}$ & $.49\left(.24^{* *}\right)$ \\
\hline \multicolumn{6}{|l|}{ Staff ratings } \\
\hline Social connections & -.07 & .01 & -.11 & -.06 & $.16\left(.02^{*}\right)$ \\
\hline Behavior in prison & $-.28^{*}$ & $-.17^{* *}$ & .02 & $-.34^{* *}$ & $.40\left(.14^{* *}\right)$ \\
\hline Reintegration prognosis & -.06 & $-.17^{* *}$ & .01 & $-.33^{* *}$ & $.37\left(.14^{* *}\right)$ \\
\hline
\end{tabular}

Sex $(0=$ male, $1=$ female $)$ was entered at Step 1 of each model to predict a given outcome variable $(z$-scored $)$, followed by all three TriPM scales ( $z$-scored) at Step 2. Multiple $R=$ omnibus correlation for full model at Step 2; $\Delta R^{2}=$ additional variance accounted for by addition of TriPM scales at Step 2

${ }^{*} p<.05 ;{ }^{* *} p<.05$

well as positive relations with total and other-drug ESI-SUP scores and NEO-FFI Extraversion, Openness, and Conscientiousness. Meanness showed unique positive associations with BHS hopelessness (total score and all subscales) and negative relations with NEO-FFI Extraversion, Openness, Agreeableness, and Conscientiousness. Finally, Disinhibition was uniquely positively related to the BHS total score and Negative Expectations subscale, ESI-SUP total score and each substance-specific problem scale, DSHI frequency and versatility, and NEO-FFI Neuroticism. Disinhibition was also negatively associated with NEO-FFI Agreeableness and Conscientiousness, as well as staff ratings of prison behavior and reintegration prognosis.

\section{Moderating Effects of Participant Sex on TriPM-Scale/Criterion-Measure Associations}

As evident from the results for Step 3 of the regression models (see Table 3), no moderating effect of sex was observed for any of the BHS or NEO-FFI variables. However, a number of differences between males and females emerged in the associations between TriPM scales and other criterion measures. Notably, in almost all cases, the associations were significant for both sexes and in the same direction but were significantly stronger in females, as evidenced by significant Sex x TriPM scale interaction terms. Specifically, Sex $x$ Disinhibition interaction effects were observed for both the ESI-bf-SP total score (interaction $B=.28, p<.05,95 \%$ confidence interval $[\mathrm{CI}]=[.03, .53])$ and Other Drug Problems scale (interaction $B=.37, p<.01,95 \% \mathrm{CI}=[.11, .63]$ ). Follow-up analyses revealed that increases in disinhibition were associated with greater changes in each of these outcomes in females $(B \mathrm{~s}=.75$ and .77 , respectively, $p \mathrm{~s}<.001$, $95 \% \mathrm{CIs}=[.52, .97]$ and $[.54,1.00])$ than in males $(B \mathrm{~s}=.47$ and .40 , respectively, $p s<.001,95 \% \mathrm{CIs}=[.35, .59]$ and [.28, .52]; see Figs. 1 and 2). A similar interaction was also observed for both DHSI scales (frequency interaction $B=.36$, $p<.05,95 \% \mathrm{CI}=[.09, .64]$; versatility interaction $B=.48$, 
Table 3 Step 3 of hierarchical regression models predicting each criterion variable

\begin{tabular}{|c|c|c|c|c|c|c|c|c|}
\hline \multirow[b]{2}{*}{ Study variable } & \multicolumn{7}{|l|}{ Step 3} & \multirow[b]{2}{*}{$\begin{array}{l}\text { Step } 3 \text { Multiple } \\
R\left(\Delta R^{2}\right)\end{array}$} \\
\hline & $\begin{array}{l}\text { Sex } \\
B\end{array}$ & $\begin{array}{l}\text { Bold } \\
B\end{array}$ & $\begin{array}{l}\text { Mean } \\
B\end{array}$ & $\begin{array}{l}\text { Dis } \\
B\end{array}$ & Bold x Sex $B$ & Mean x Sex $B$ & Dis $x \operatorname{Sex} B$ & \\
\hline \multicolumn{9}{|l|}{ Beck Hopelessness Scale (BHS) } \\
\hline Total & .03 & $-.32^{* *}$ & $.22^{* *}$ & .11 & .06 & .22 & -.04 & $.41(.01)$ \\
\hline Feeling about the future & -.10 & $-.26^{* *}$ & $.21^{* *}$ & .02 & .13 & .21 & -.01 & $.32(.01)$ \\
\hline Loss of motivation & .12 & $-.25^{* *}$ & $.19^{* *}$ & .11 & -.05 & .32 & -.19 & $.36(.01)$ \\
\hline Negative expectations & .02 & $-.31^{* *}$ & $.16^{*}$ & $.16^{*}$ & .08 & .00 & .12 & $.40(.00)$ \\
\hline \multicolumn{9}{|c|}{ Externalizing Spectrum Inventory (ESI) } \\
\hline Total substance use problems & .00 & .05 & .01 & $.47^{* *}$ & .13 & .04 & $.28^{*}$ & $.59\left(.02^{* *}\right)$ \\
\hline Alcohol use problems & -.10 & .07 & .02 & $.36^{* *}$ & .05 & -.08 & .26 & $.45(.01)$ \\
\hline Marijuana use problems & .01 & .03 & -.02 & $.41^{* *}$ & .10 & .17 & .07 & $.47(.01)$ \\
\hline Other drug use problems & .11 & .03 & .02 & $.40^{* *}$ & .17 & .01 & $.37^{* *}$ & $.57\left(.04^{* *}\right)$ \\
\hline \multicolumn{9}{|c|}{ Deliberate Self-Harm Inventory (DSHI) } \\
\hline Frequency (log-transformed) & $.38^{* *}$ & -.08 & .08 & $.22^{* *}$ & .00 & .04 & $.36^{*}$ & $.47\left(.03^{* *}\right)$ \\
\hline Versatility & $.31^{* *}$ & -.03 & .03 & $.21^{* *}$ & -.07 & -.31 & $.48^{* *}$ & $.41\left(.03^{* *}\right)$ \\
\hline \multicolumn{9}{|l|}{ NEO Five-Factor Inventory } \\
\hline Neuroticism & $.51^{* *}$ & $-.38^{* *}$ & .11 & $.29^{* *}$ & -.04 & -.15 & .20 & $.61(.01)$ \\
\hline Extraversion & -.07 & $.42^{* *}$ & $-.21^{* *}$ & .00 & -.07 & .12 & .03 & $.41(.00)$ \\
\hline Openness & .11 & $.19^{* *}$ & $-.33^{* *}$ & -.08 & -.04 & .26 & .15 & $.36\left(.02^{*}\right)$ \\
\hline Agreeableness & $-.35^{* *}$ & -.08 & $-.38^{* *}$ & $-.23^{* *}$ & .11 & -.12 & .12 & $.58(.00)$ \\
\hline Conscientiousness & .12 & $.18^{* * *}$ & $-.26^{* *}$ & $-.24^{* *}$ & .11 & -.04 & -.15 & $.50(.01)$ \\
\hline \multicolumn{9}{|l|}{ Staff ratings } \\
\hline Social connections & -.04 & .11 & $-.16^{*}$ & .00 & $-.32^{* *}$ & .26 & -.25 & $.23\left(.03^{*}\right)$ \\
\hline Behavior in prison & -.19 & -.07 & .02 & $-.25^{* *}$ & $-.28^{* *}$ & -.04 & $-.28^{*}$ & $.45\left(.04^{* *}\right)$ \\
\hline Reintegration prognosis & .05 & -.10 & -.01 & $-.25^{* *}$ & -.17 & .07 & -.29 & $.40(.02)$ \\
\hline
\end{tabular}

Results are from Step 3 of the hierarchical regression model presented in Table 2; TriPM-by-sex interaction terms were added at this step. Sex was coded $0=$ male, $1=$ female. Bold = Boldness; Mean = Meanness; Dis $=$ Disinhibition. Multiple $R=$ omnibus correlation for full model at Step 3; $\Delta R^{2}=$ additional variance accounted for by addition of TriPM-by-sex interaction terms at Step 3

${ }^{*} p<.05 ;{ }^{* *} p<.01$

$p<.01,95 \% \mathrm{CI}=[.19, .77])$. In particular, high disinhibition was associated with greater increases in self-harm frequency and versatility in females $(B s=.58$ and .69 , respectively, $p s<.001,95 \% \mathrm{CIs}=[.34, .83]$ and $[.44, .94])$ than in males $(B s=.22$ and .21 , respectively, $p s<.005,95 \% \mathrm{CIs}=[.09, .35]$ and $[.07, .34]$; see Figs. 3 and 4).

With regard to staff ratings, a Sex x Boldness interaction was found for social connections outside the prison (interaction $B=-.32, p<.01,95 \% \mathrm{CI}=[-.55,-.09]$ ); followup analyses revealed a negative association for females $(B=-.21, p<.05,95 \% \mathrm{CI}=[-.40,-.02])$ and none for males $(B=.11, p=.10,95 \% \mathrm{CI}=[-.02, .24]$; see Fig. 5). Unique Sex x TriPM interactions were also observed for boldness and disinhibition in predicting ratings of prison behavior (boldness interaction $B=-.28, p<.01,95 \% \mathrm{CI}=[-.50,-.07]$; disinhibition interaction $B=-.28, p<.05,95 \% \mathrm{CI}=[-.57$, -.01]). Follow-up analyses revealed a significant negative predictive effect for boldness in females $(B=-.35, p<.001$, $95 \% \mathrm{CI}=[-.53,-.18])$, but not males $(B=-.07, p=.25,95 \%$
$\mathrm{CI}=[-.19, .05]$; see Fig. 6). Although disinhibition was associated with poorer prison behavior in both sexes, the effect for females was somewhat stronger than for males $(B \mathrm{~s}=-.54$ and -.25 , respectively, $p \mathrm{~s}<.001,95 \% \mathrm{CIs}=[-.79$, -.29] and [-.38, -.12]; see Fig. 7).

\section{Discussion}

This study sought to elucidate sex differences in the nomological network of the triarchic model of psychopathy among incarcerated individuals, adding to scientific understanding about the model's external validity. Findings generally complement and extend prior work comparing males and females in non-incarcerated populations and overcome an important limitation of the existing literature: a reliance on the PCL-R and related measures, which emphasize crime-related aspects of psychopathy to the exclusion of adaptive features. The triarchic model of psychopathy 


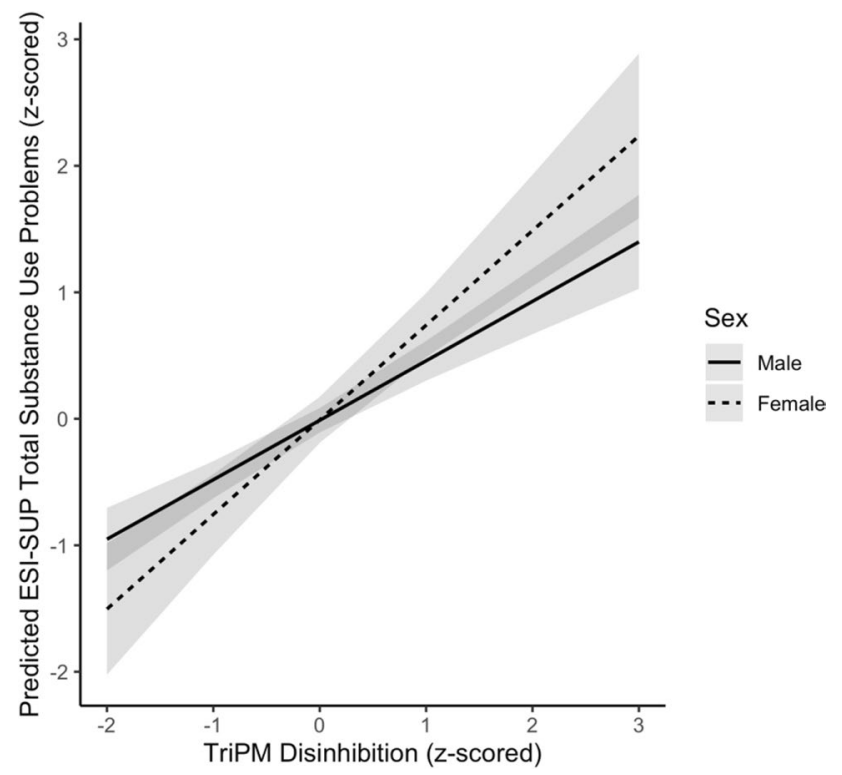

Fig. 1 Sex x Disinhibition interaction predicting total substance use problems; $B \mathrm{~s}=.47$ for males $(95 \% \mathrm{CI}=[.35, .59])$ and .75 for females $(95 \% \mathrm{CI}=[.52, .97]), p \mathrm{~s}<.001$

is designed to capture dispositional characteristics that may be expressed in a variety of phenotypes, including engagement in crime. The current study examined other manifestations of the triarchic traits - i.e., patterns of relations to other relevant constructs, such as personality and psychopathology - within a sample characterized by elevated engagement in crime, as well as investigating sex differences in these patterns.

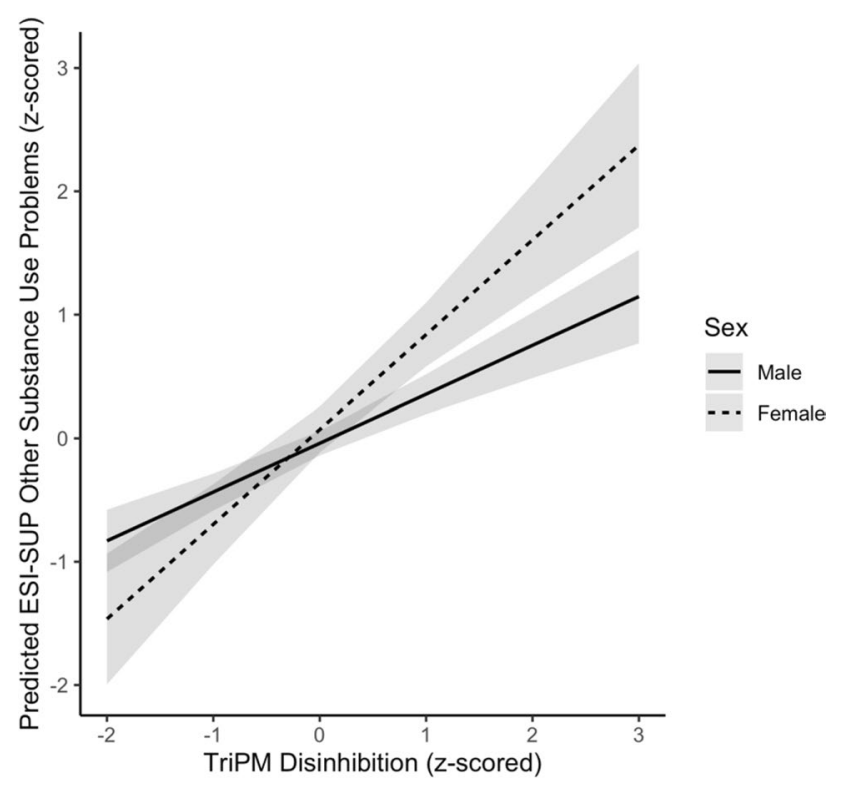

Fig. 2 Sex x Disinhibition interaction predicting other (non-alcohol, non-marijuana) drug use problems; $B \mathrm{~s}=.40$ for males $(95 \% \mathrm{CI}=[.28$, $.52])$ and .77 for females $(95 \% \mathrm{CI}=[.54,1.00]), p s<.001$

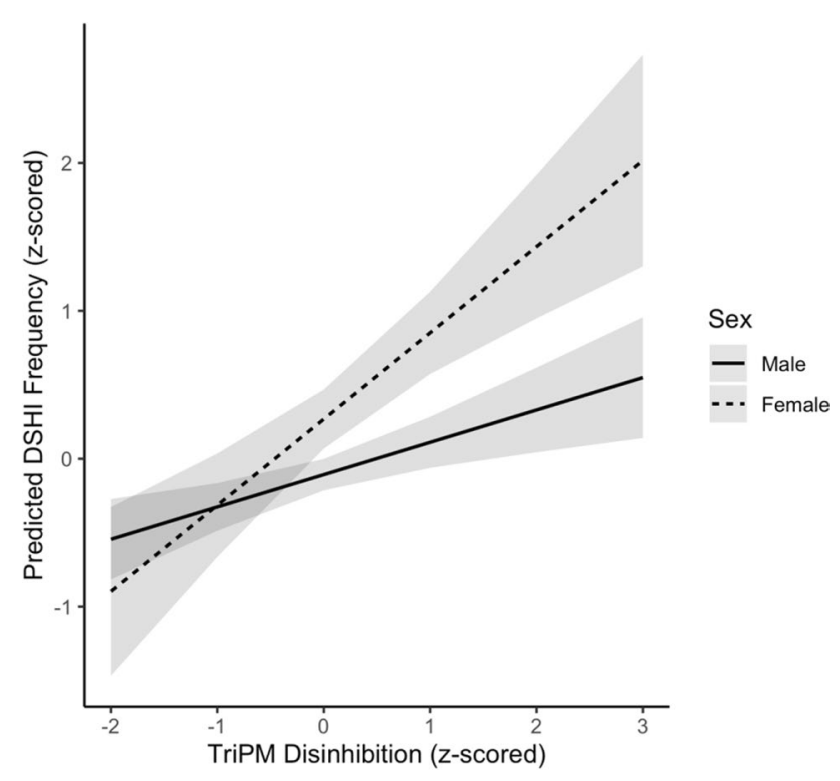

Fig. 3 Sex $x$ Disinhibition interaction predicting the frequency of self-harm behaviors; $B=.22$ for males $(95 \% \mathrm{CI}=[.09, .35]), p<.005$, and $B=.58$ for females $(95 \% \mathrm{CI}=[.34, .83]), p<.001$

\section{The Triarchic Model in a Prison Sample}

The current results advance scientific understanding of the triarchic model in a prison sample. Broadly, findings were consistent with hypotheses based on previous studies. Consistent with the theoretical conceptualization of boldness and with prior research (e.g., Sica et al., 2015), we found in this mixed-sex prison sample that TriPM Boldness was

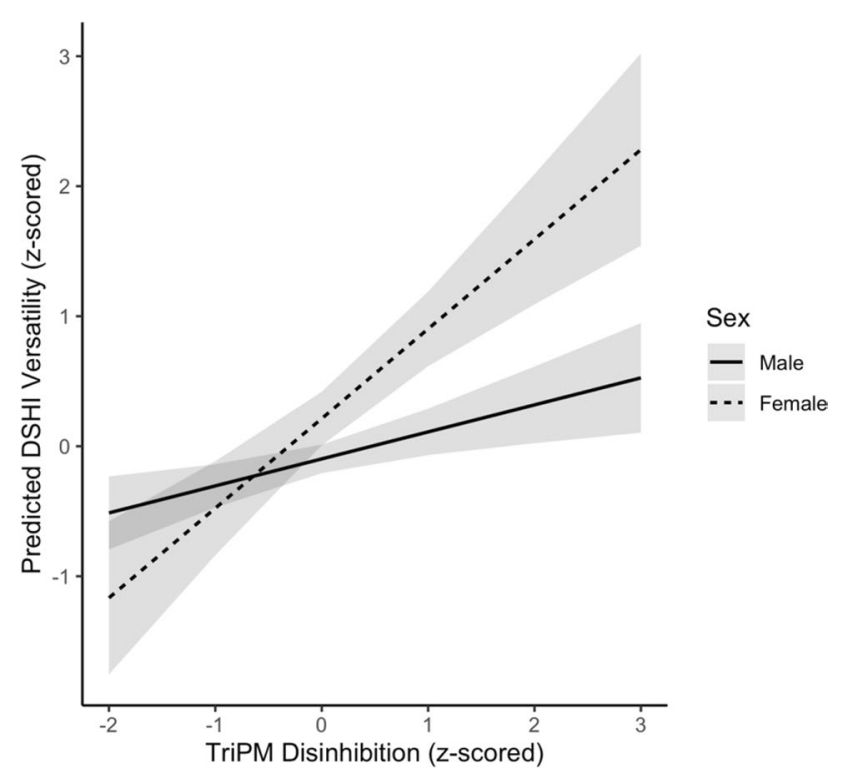

Fig. 4 Sex $x$ Disinhibition interaction predicting the versatility of self-harm behaviors; $B=.21$ for males $(95 \% \mathrm{CI}=[.07, .34]), p<.005$, and $B=.69$ for females $(95 \% \mathrm{CI}=[.44, .94]), p<.001$ 


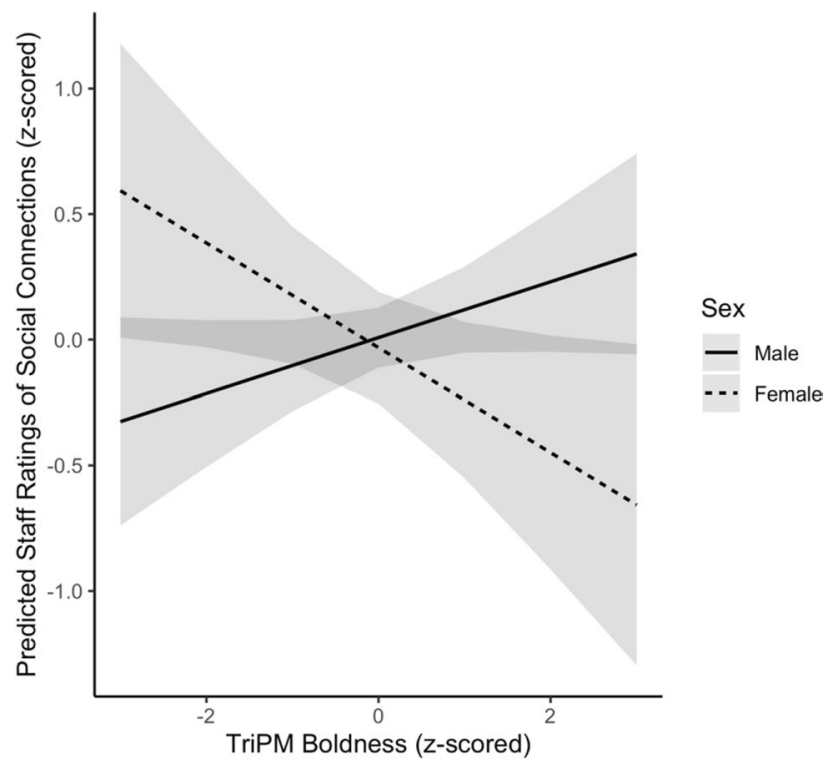

Fig. 5 Sex $x$ Boldness interaction predicting staff ratings of social connections outside the prison; $B=.11$ for males $(95 \% \mathrm{CI}=[-.02$, $.24]), p=.10$, and $B=-.21$ for females (95\% CI=[-.40, -.02]), $p<.05$

negatively associated with certain maladaptive constructs such as neuroticism and hopelessness, suggesting it adequately represents some aspects of psychological resilience against distress in an incarcerated sample (see Gottfried et al., 2019). Interestingly, and contrary to hypotheses, boldness was unrelated to self-harm in this sample; it may that this trait is less closely tied to behavioral expressions of distress than

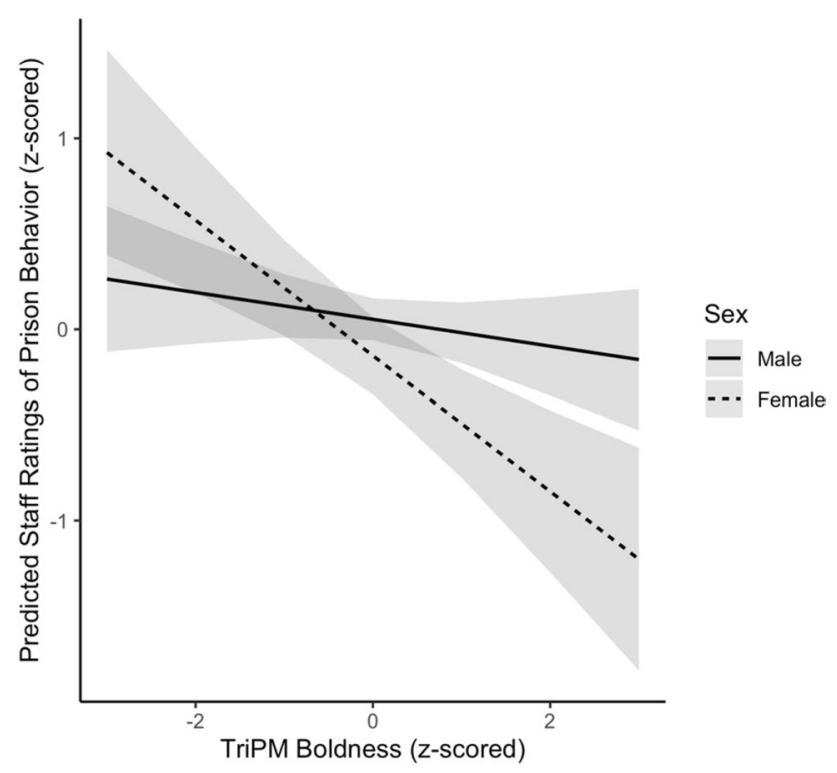

Fig. 6 Sex $\mathrm{x}$ Boldness interaction predicting staff ratings of prison behavior; $B=-.07$ for males $(95 \% \mathrm{CI}=[-.19, .05]), p=.25$, and $B=-.35$ for females $(95 \% \mathrm{CI}=[-.53,-.18]), p<.001$

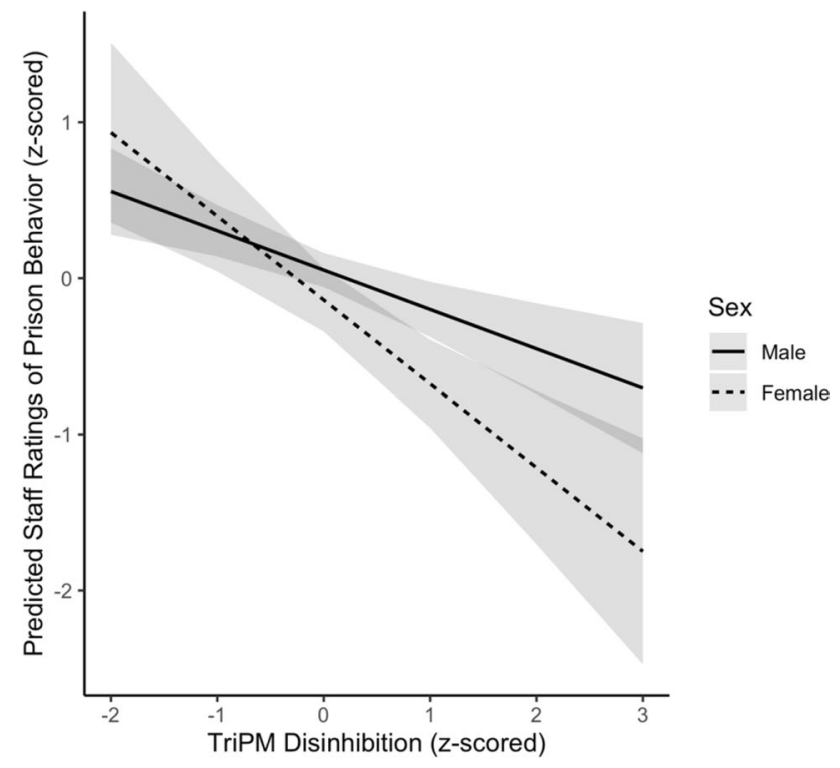

Fig. 7 Sex $\mathrm{x}$ Disinhibition interaction predicting staff ratings of prison behavior; $B \mathrm{~s}=-.25$ for males $(95 \% \mathrm{CI}=[-.38,-.12])$ and -.54 for females $(95 \% \mathrm{CI}=[-.79,-.29]), p \mathrm{~s}<.001$

to the psychological experience itself. Importantly, despite its generally negative relations with distress measures, boldness was predictive of greater substance use problems and lower staff ratings of prison behavior and reintegration prognosis following release. These results are in line with other findings suggesting that boldness does not merely index positive adjustment (Lilienfeld et al., 2012, 2018; cf. Miller \& Lynam, 2012). Multiple studies have found positive associations between boldness and various forms of maladaptive behavior (e.g., Anestis et al., 2018; Baroncelli et al., in press; Coffey et al., 2018; Hicks et al., 2014), including in prison samples (Sellbom et al., 2018). Notably, however, a previous study of incarcerated males found boldness to be associated with lower structured clinical judgments of risk for future violence (Sellbom et al., 2018), in contrast to the present results regarding current prison behavior and reintegration prognosis. Further research is needed to understand boldness and behavior in correctional settings.

Relations between TriPM Meanness and FFM traits were generally consistent with expectations, particularly the strong negative association with agreeableness. In this prison sample, as in non-incarcerated samples, triarchic meanness is closely linked to the FFM construct of antagonism (i.e., low agreeableness; see Poy et al., 2014). Interestingly, and contrary to hypotheses, meanness was uniquely associated with low conscientiousness, even after accounting for its relationship with disinhibition. It may be that the uncaring, detached features of meanness are expressed as disregard for personal responsibilities in the prison context; however, this association did not appear to extend to overt 
disciplinary problems, given the null correlation between meanness and staff ratings of prison behavior. Finally, meanness was positively associated with all facets of hopelessness but was unrelated to substance problems or self-harm. Meanness includes a prominent element of cynicism that may result in elevated hopelessness scores (e.g., Berg et al., 2013; Sellbom et al., 2018) despite null relations with other distress-related problems.

Consistent with its nomological net, disinhibition was uniquely associated with high neuroticism, low conscientiousness, and low agreeableness. Further, as expected, disinhibition was positively related to substance use problems, hopelessness, and self-harm. This finding is consistent with prior evidence that disinhibition constitutes a liability factor for myriad forms of psychopathology that involve poor emotional or behavioral control (Buchman-Schmitt et al., 2017; Patrick et al., 2013a, b; Perkins et al., 2019). Finally, negative associations were noted for disinhibition with staff ratings of prison behavior and reintegration prognosis. These are consistent with a prior study using structured risk assessments (Sellbom et al., 2018) and may reflect the persistently unrestrained, irresponsible tendencies exhibited by those high in disinhibition both inside and outside the prison setting.

\section{Sex Differences in External Correlates of the Triarchic Traits}

Regarding the central theme of the current paper, the main result was that the similarities between sexes outnumbered the differences. First, males and females did not differ in mean scores on TriPM Boldness or Meanness. This finding accords with some prior prison studies utilizing the Psychopathic Personality Inventory (PPI; Lilienfeld \& Andrews, 1996), another personality-based measure of psychopathy, which have found few mean-level differences between males and females on fearless dominance (akin to boldness; e.g., Sellbom et al., 2017). However, our result is in contrast to the literature for undergraduates and forensic mental health evaluees reviewed above, in which higher boldness and meanness scores have typically been reported for males as compared to females. One explanation may be that females in our unselected prison sample were less affected by normative gender socialization forces over development than community females, contributing to their engagement in crime as well as their relatively elevated boldness and meanness (see Letendre, 2007; Scott \& Mikell, 2019). Relatively similar levels of boldness and meanness across sexes would plausibly be observed in an unselected prison sample such as ours, containing individuals with and without mental illness, but not in a forensic sample (Anestis et al., 2019; Sellbom et al., 2017), in which mental illness may have played a greater role than gender socialization in females' engagement in crime (Blanchette \& Brown, 2019; Fazel \& Grann, 2006; Flynn et al., 2011).

As expected, participant sex did not moderate observed relations of boldness with most criterion variables. Boldness is theorized to involve reduced sensitivity of the brain's defensive reactivity system to cues signaling threat or punishment (e.g., Patrick et al., 2019; Yancey et al., 2016). Operating from this perspective, it appears that dispositional fearlessness manifested similarly for males and females in the current study - except in terms of its impact on staff ratings of behavior within the prison and social connections outside, where in each case associations for boldness were more negative in females than in males. One potential interpretation of this unanticipated result is that some aspects of boldness may be viewed by others as adaptive in males but maladaptive in females; for example, social dominance may be seen by raters as either "leadership" or "pushiness," depending on the sex of the evaluee. Another possibility is that boldness may be expressed more in terms of manipulativeness or erratic behaviors in incarcerated females than in males. For instance, the affective-interpersonal (Factor 1) features of psychopathy are closely linked to borderline personality disorder symptoms in females, but not males (Verona et al., 2012). Females high in boldness might rely on manipulation or relational aggression to achieve their goals to a greater extent than high-bold males (see also Crick \& Grotpeter, 1995; Robbins et al., 2003). These behaviors could plausibly result in poorer social relationships and more disciplinary issues inside the prison. However, since this finding was not hypothesized, it requires replication and should be interpreted with caution until replicated.

Based on the literature, we anticipated that sex would moderate the expression of meanness in particular with regard to distress symptomatology and personality. As meanness involves dysfunction in affective and affiliative systems (Palumbo et al., 2020; Viding \& McCrory, 2019), its expression was hypothesized to be influenced by gender norms and females' socialization to be warm and cooperative (Eagly, 2009). Although no Sex x Meanness interaction effects were significant in this sample, some approached significance, with meanness tending to relate more strongly to increases in BHS Lack of Motivation and decreases in DSHI Versatility in females than males. Although the former effect would be consistent with hypotheses, further research is needed with larger samples to achieve adequate power.

The majority of points of divergence between sexes concerned the trait of disinhibition. First, mean levels of disinhibition were higher for females than males in this prison sample. This finding contrasts with prior research in a forensic mental health sample that demonstrated higher disinhibition among males (Anestis et al., 2019), and with undergraduate samples that showed similar levels across sex (e.g., Drislane \& Patrick, 2017). Higher levels of disinhibition may need 
to be present, on average, for females to engage in crime, given that socialization processes may otherwise inhibit such behavior (Leve et al., 2005).

Sex differences were also observed in the associations of disinhibition with other variables. In particular, TriPM Disinhibition in females was more closely associated with selfharm than in males. Consistent with these findings, impulsivity, aggression, and hostility - constructs central to the nomological network of disinhibition - are more often manifested as self-directed violence and self-harm in females than in males (Sadeh et al., 2011). Related concepts of emotion dysregulation, affective instability, and ineffective emotion regulation strategies are also elevated among females high in psychopathy relative to their male counterparts (de Vogel \& Lancel, 2016; Kreis \& Cooke, 2011; Sica et al., 2015; Verona et al., 2012). Females may be socialized to express problems through emotional dysregulation (internalizing; Keenan $\&$ Shaw, 1997). Another possible explanation involves the fact that disinhibition is influenced by the early environment (Tuvblad et al., 2019) and is correlated with a history of abuse (Gottfried et al., 2019; Graham et al., 2012; Verona et al., 2005). Given that trauma is extremely common among incarcerated females (DeHart et al., 2014; Lynch et al., 2012), such experiences could play a role in the sex-differentiated expression of disinhibition as emotion dysregulation. This explanation could also account for our finding that disinhibition was associated with greater increases in substance use among females than males, as the association between post-traumatic stress and substance use depends on the presence of emotion dysregulation (Tull et al., 2015), especially among women (Bornovalova et al., 2009). Although our substance use results contrast with findings from a forensic mental health clinic sample (Anestis et al., 2019), it is possible that the lower rate of comorbid serious mental illness in our unselected prison sample resulted in clearer sex differences in the degree to which substance use is driven by distress. Nevertheless, as with other mechanistic possibilities offered throughout this paper, these inferences remain to be explicitly tested.

Disinhibition also predicted staff ratings of misbehavior in prison to a greater degree in females than in males. Such a result is particularly important given that among incarcerated females, PCL-R scores do not predict violent behavior, verbal aggression, or noncompliance within the prison setting (Salekin et al., 1997). In this respect, as a trait-based approach rooted in models of personality, the triarchic model may hold promise for improving risk assessment among incarcerated females. However, this result requires replication.

\section{Strengths, Limitations, and Directions}

A notable strength of the current study is its use of a mixedsex prison sample and the examination of external correlates considered to be of particular importance to this population (e.g., substance problems, self-harm, institutional behavior problems). This design allowed us to undertake, for the first time in an unselected prison sample, direct comparisons of the external correlates of the triarchic model across males and females. In addition, our sample was composed of individuals charged with serious crimes and who had several prior convictions; thus, the crime-history profile of our participants was distinctly severe.

The current study also has certain limitations. First, our sample consisted of incarcerated individuals from the nation of Italy, and thus our results may not generalize to individuals from other cultures and ethnic backgrounds. In addition, although the inclusion of staff-rated criterion variables was a strength, the psychometric properties of these measures are unknown, and it is unclear to what degree gender bias may have played a role in ratings. However, the incorporation of multiple sources of data in these ratings (e.g., police reports) may mitigate these concerns somewhat. Finally, although the focus of this study was on external validation, there is also a need for research on the internal psychometric properties of the TriPM in prison samples. This work will require larger samples of incarcerated females in particular (here, $n=83$ ) and could include structural analyse ${ }^{3}$ and examinations of measurement invariance across sexes. A larger sample would also allow for an examination of the interactive and configural effects of triarchic dimensions (e.g., variants of psychopathy) in predicting important clinical criteria across sex.

\section{Conclusion}

Despite these limitations, our findings represent a noteworthy contribution that both extends our understanding of the external validity of psychopathic traits across male and female participants, and contributes to the growing body of research supporting the role of personality-based models in framing this complex condition. As a whole, our results suggest that the nomological net of the triarchic model of psychopathy is largely similar across incarcerated males and females. When associations with external criteria varied by

\footnotetext{
${ }^{3}$ At the request of an anonymous reviewer, we conducted a structural analysis of the TriPM item set using exploratory structural equation modeling (Latzman et al., 2019; Paiva et al., 2020; Patrick et al., 2021; Somma et al., 2019), the preferred method for modeling the structure of personality inventories (Hopwood \& Donnellan, 2010; Marsh et al., 2014). The fit of this model in the current study sample was acceptable according to the root mean square error of approximation criterion (RMSEA=.06), but somewhat less than acceptable according to the comparative fit index criterion $(\mathrm{CFI}=.80)$. Given our modest sample size and concerns that have been raised about factor-structure comparability of psychopathy inventories in prisoner versus community participants (Ruchensky et al., 2018), these results should be considered tentative and in need of further investigation.
} 
sex, these differences were generally attributable to magnitude (i.e., larger effects for females) rather than kind (e.g., opposing effects for females and males). The broad similarities in the nomological net of the triarchic model between males and females may suggest that these liabilities are relatively specific and invariant in their manifestations across sexes. The triarchic model represents an important step forward in the characterization of psychopathic predispositions separately from their antisocial outcomes, laying the groundwork for greater scientific understanding of sex similarities and differences in psychopathy.

Supplementary Information The online version contains supplementary material available at https://doi.org/10.1007/s10862-021-09897-w.

Funding Open access funding provided by Università degli Studi di Firenze within the CRUI-CARE Agreement. Co-authors of this article were supported by the National Institute of Mental Health of the National Institutes of Health under award number F31MH122096 (E.R.P.), and by U.S. Army grant W911NF-14-1-0018 (C.J.P.). The content of this paper is solely the responsibility of the authors and does not necessarily reflect the official views of the U.S. Government, National Institutes of Health, Department of Defense, Department of the Army, Department of Veterans Affairs, or U.S. Recruiting Command." Keanan J. Joyner's effort was supported by a Ford Foundation Predoctoral Fellowship administered by the National Academies of Sciences, Engineering, and Medicine

\section{Availability of Data and Material (Data transparency): on request}

\section{Declarations}

Ethical Approval All procedures performed in studies involving human participants were in accordance with the ethical standards of the institutional and/or national research committee and with the 1964 Declaration of Helsinki and its later amendments or comparable ethical standards.

Informed Consent All participants were informed of the study's aims and gave their informed consent before enrolling in the study.

Experiment Participants Authorization to collect data from the 10 prisons was obtained from the National Administration of Prisons (Dipartimento dell'Amministrazione Penitenziara; DAP) and its local branches for the northern Italian region of Lombardy and central Italian region of Tuscany. Procedures for the study complied fully with the ethical standards as laid down in the 1964 Declaration of Helsinki and its later amendments and were approved by the Institutional Review Board of the University of Firenze as well as by the DAP.

Conflict of Interest ClaudioSica,Emily Perkins, KeananJoyner, Corrado Caudek, Gioia Bottesi, Maria Caruso, Paolo Giulini, Marta Ghisi, and Christopher J. Patrick declare that they have no conflict of interest.

Open Access This article is licensed under a Creative Commons Attribution 4.0 International License, which permits use, sharing, adaptation, distribution and reproduction in any medium or format, as long as you give appropriate credit to the original author(s) and the source, provide a link to the Creative Commons licence, and indicate if changes were made. The images or other third party material in this article are included in the article's Creative Commons licence, unless indicated otherwise in a credit line to the material. If material is not included in the article's Creative Commons licence and your intended use is not permitted by statutory regulation or exceeds the permitted use, you will need to obtain permission directly from the copyright holder. To view a copy of this licence, visit http://creativecommons.org/licenses/by/4.0/.

\section{References}

Anestis, J. C., Anestis, M. D., \& Preston, O. C. (2018). Psychopathic Personality Traits As a Form of Dispositional Capability for Suicide. Psychiatry Research, 262, 193-202. https://doi.org/10. 1016/j.psychres.2018.02.003

Anestis, J. C., Preston, O. C., Harrop, T. M., \& Sellbom, M. (2019). The intersection of sociodemographic characteristics within the nomological network of the triarchic psychopathy model in a forensic sample. Journal of Criminal Justice, 61, 13-25. https:// doi.org/10.1016/j.jcrimjus.2019.02.001

Baroncelli, A., Perkins, E. R., Ciucci, E., Frick, P. J., Patrick, C. J., \& Sica, C. (in press). Triarchic model traits as predictors of bullying and cyberbullying in adolescence. Journal of Interpersonal Violence.

Barry, C. T., Frick, P. J., DeShazo, T. M., McCoy, M., Ellis, M., \& Loney, B. R. (2000). The importance of callous-unemotional traits for extending the concept of psychopathy to children. Journal of Abnormal Psychology, 109(2), 335-340. https://doi.org/10.1037/ 0021-843X.109.2.335

Beck, A. T., \& Steer, R. A. (1993). Manual for the Beck Hopelessness Scale (2nd ed.). Psychological Corporation.

Berg, J. M., Lilienfeld, S. O., Reddy, S. D., Latzman, R. D., Roose, A., Craighead, L. W., \& Raison, C. L. (2013). The Inventory of Callous and Unemotional Traits: A construct-validational analysis in an at-risk sample. Assessment, 20, 532-544. https://doi.org/ $10.1177 / 1073191112474338$

Blanchette, K., \& Brown, S. L. (2019). Female offenders. In R. D. Morgan (Ed.), The SAGE encyclopedia of criminal psychology (pp. 490-495). SAGE Publications, Inc.

Blonigen, D. M., Hicks, B. M., Krueger, R. F., Patrick, C. J., \& Iacono, W. G. (2005). Psychopathic personality traits: Heritability and genetic overlap with internalizing and externalizing psychopathology. Psychological Medicine, 35, 637-648. https://doi.org/ 10.1017/S0033291704004180

Bolt, D. M., Hare, R. D., Vitale, J. E., \& Newman, J. P. (2004). A Multigroup Item Response Theory Analysis of the Psychopathy Checklist-Revised. Psychological Assessment, 16(2), 155-168. https://doi.org/10.1037/1040-3590.16.2.155

Bornovalova, M. A., Ouimette, P., Crawford, A. V., \& Levy, R. (2009). Testing gender effects on the mechanisms explaining the association between post-traumatic stress symptoms and substance use frequency. Addictive Behaviors, 34(8), 685-692. https://doi.org/ 10.1016/j.addbeh.2009.04.005

Brislin, S. J., Drislane, L. E., Smith, S. T., Edens, J. F., \& Patrick, C. J. (2015). Development and validation of triarchic psychopathy scales from the Multidimensional Personality Questionnaire. Psychological Assessment, 27, 838-851. https://doi.org/10.1037/pas0000087

Buchman-Schmitt, J. M., Brislin, S. J., Venables, N. C., Joiner, T. E., \& Patrick, C. J. (2017). Trait liabilities and specific promotive processes in psychopathology: The example of suicidal behavior. Journal of Affective Disorders, 216, 100-108. https://doi.org/10. 1016/j.jad.2016.09.050

Cale, E. M., \& Lilienfeld, S. O. (2002). Sex differences in psychopathy and antisocial personality disorder: A review and integration. Clinical Psychology Review, 22, 1179-1207. https://doi.org/10. 1016/S0272-7358(01)00125-8

Cameron, J. J., \& Stinson, D. A. (2019). Gender (mis)measurement: Guidelines for respecting gender diversity in psychological 
research. Social and Personality Psychology Compass, 13(11), e12506. https://doi.org/10.1111/spc3.12506

Cerutti, R., Manca, M., Presaghi, F., \& Gratz, K. L. (2011). Prevalence and clinical correlates of deliberate self-harm among a community sample of Italian adolescents. Journal of Adolescence, 34, 337-347. https://doi.org/10.1016/j.adolescence.2010.04.004

Cleckley, H. (1941). The mask of sanity. Mosby.

Coffey, C. A., Cox, J., \& Kopkin, M. R. (2018). Examining the relationships between the triarchic psychopathy constructs and behavioral deviance in a community sample. Journal of Personality Disorders, 32, 57-69. https://doi.org/10.1521/pedi_2017_31_288

Coid, J., Yang, M., Ullrich, S., Zhang, T., Sizmur, S., Roberts, C., Farrington, D. P., \& Rogers, R. D. (2009). Gender differences in structured risk assessment: Comparing the accuracy of five instruments. Journal of Consulting and Clinical Psychology, 77(2), 337. https://doi.org/10.1037/a0015155

Cooke, D. J., Michie, C., Hart, S. D., \& Clark, D. A. (2004). Reconstructing psychopathy: Clarifying the significance of antisocial and socially deviant behavior in the diagnosis of psychopathic personality disorder. Journal of Personality Disorders, 18, 337357. https://doi.org/10.1521/pedi.2004.18.4.337

Cohen, J. (1988). Statistical power analysis for the behavioral sciences (2nd ed.). Hillsdale. NJ: Erlbaum.

Costa, P. T., Jr., \& McCrae, R. R. (1992). Revised NEO Personality Inventory (NEO-PI-R) and NEO Five-Factor Inventory (NEOFFI) professional manual. Odessa, FL: Psychological Assessment Resources.

Crego, C., \& Widiger, T. A. (2016). Cleckley's psychopaths: Revisited. Journal of Abnormal Psychology, 125, 75-87. https://doi.org/10. 1037/abn0000130

Crick, N. R., \& Grotpeter, J. K. (1995). Relational aggression, gender, and social-psychological adjustment. Child Development, 66, 710-722. https://doi.org/10.1111/j.1467-8624.1995.tb00900.x

Cronbach, L. J., \& Meehl, P. E. (1955). Construct validity in psychological tests. Psychological Bulletin, 52, 281-302. https://doi. org/10.1037/h0040957

de Vogel, V., \& Lancel, M. (2016). Gender Differences in the Assessment and Manifestation of Psychopathy: Results From a Multicenter Study in Forensic Psychiatric Patients. International Journal of Forensic Mental Health, 15(1), 97-110. https://doi. org/10.1080/14999013.2016.1138173

DeHart, D., Lynch, S., Belknap, J., Dass-Brailsford, P., \& Green, B. (2014). Life history models of female offending: The roles of serious mental illness and trauma in women's pathways to jail. Psychology of Women Quarterly, 38, 138-151. https://doi.org/ 10.1177/0361684313494357

Derefinko, K. J., \& Lynam, D. R. (2006). Convergence and divergence among self-report psychopathy measures: A personality-based approach. Journal of Personality Disorders, 20, 261-280. https:// doi.org/10.1521/pedi.2006.20.3.261

Drislane, L. E., \& Patrick, C. J. (2017). Integrating alternative conceptions of psychopathic personality: A latent variable model of triarchic psychopathy constructs. Journal of Personality Disorders, 31, 110-132. https://doi.org/10.1521/pedi_2016_30_240

Drislane, L. E., Patrick, C. J., \& Arsal, G. (2014). Clarifying the content coverage of differing psychopathy inventories through reference to the Triarchic Psychopathy Measure. Psychological Assessment, 26, 350-362. https://doi.org/10.1037/a0035152

Eagly, A. H. (2009). The His and Hers of Prosocial Behavior: An Examination of the Social Psychology of Gender. American Psychologist, 64(8), 644-658.

Edens, J. F., Campbell, J. S., \& Weir, J. M. (2007). Youth psychopathy and criminal recidivism: A meta-analysis of the psychopathy checklist measures. Law and Human Behavior, 31, 53-75. https://doi.org/10.1007/s10979-006-9019-y
Essau, C. A., Sasagawa, S., \& Frick, P. J. (2006). Callous-unemotional traits in a community sample of adolescents. Assessment, 13(4), 454-469.

Falkenbach, D. M., Reinhard, E. E., \& Larson, F. R. R. (2017). Theory based gender differences in psychopathy subtypes. Personality and Individual Differences, 105, 1-6. https://doi.org/10.1016/j. paid.2016.09.023

Fanti, K. A., Kyranides, M. N., Drislane, L. E., Colins, O. F., \& Andershed, H. (2016). Validation of the Greek Cypriot translation of the triarchic psychopathy measure. Journal of Personality Assessment, 98(2), 146-154. https://doi.org/10.1080/00223891.2015.1077452

Fazel, S., \& Grann, M. (2006). The Population Impact of Severe Mental Illness on Violent Crime. American Journal of Psychiatry, 163(8), 1397-1403. https://doi.org/10.1176/ajp.2006.163.8.1397

Fliege, H., Kocalevent, R., Walter, O. B., Beck, S., Gratz, K. L., Gutierrez, P. M., et al. (2006). Three assessment tools for deliberate self-harm and suicide behavior: evaluation and psychopathological correlates. Journal of Psychosomatics Research, 61, 113-121. https://doi.org/ 10.1016/j.jpsychores.2005.10.006

Flynn, S., Abel, K. M., While, D., Mehta, H., \& Shaw, J. (2011). Mental illness, gender and homicide: A population-based descriptive study. Psychiatry Research, 185(3), 368-375. https://doi.org/10.1016/j. psychres.2010.07.040

Forouzan, E., \& Cooke, D. J. (2005). Figuring out la femme fatale: Conceptual and assessment issues concerning psychopathy in females. Behavioral Sciences and the Law, 23, 765-778. https:// doi.org/10.1002/bsl.669

Forth, A. E., Brown, S. L., Hart, S. D., \& Hare, R. D. (1996). The assessment of psychopathy in male and female noncriminals: Reliability and validity. Personality and Individual Differences, 20, 531-543. https://doi.org/10.1016/0191-8869(95)00221-9

Gottfried, E. D., Harrop, T. M., Anestis, J. C., Venables, N. C., \& Sellbom, M. (2019). An examination of triarchic psychopathy constructs in female offenders. Journal of Personality Assessment, 101, 455-467. https://doi.org/10.1080/00223891.2018. 1502193

Graham, N., Kimonis, E. R., Wasserman, A. L., \& Kline, S. M. (2012). Associations among childhood abuse and psychopathy facets in male sexual offenders. Personality Disorders: Theory, Research, and Treatment, 3, 66-75. https://doi.org/10.1037/a0025605

Gratz, K. L. (2001). Measurement of deliberate self-harm: Preliminary data on the Deliberate Self-Harm Inventory. Journal of Psychopathology and Behavioral Assessment, 23, 253-263. https://doi. org/10.1023/A:1012779403943

Hamburger, M. E., Lilienfeld, S. O., \& Hogben, M. (1996). Psychopathy, gender, and gender roles: Implications for antisocial and histrionic personality disorders. Journal of Personality Disorders, 10, 41-55. https://doi.org/10.1521/pedi.1996.10.1.41

Hare, R. D. (2003). Manual for the Revised Psychopathy Checklist (2nd ed.). . Multi-Health Systems.

Hare, R. D., \& Neumann, C. S. (2008). Psychopathy as a clinical and empirical construct. Annual Review of Clinical Psychology, 4, 217-246. https://doi.org/10.1146/annurev.clinpsy.3.022806.091452

Hicks, B. M., Iacono, W. G., \& McGue, M. (2014). Identifying childhood characteristics that underlie premorbid risk for substance use disorders: socialization and boldness. Development and Psychopathology, 26, 141-157. https://doi.org/10.1017/ S0954579413000862

Hopwood, C. J., \& Donnellan, M. B. (2010). How should the internal structure of personality inventories be evaluated? Personality and Social Psychology Review, 14(3), 332-346. https://doi.org/10. 1177/1088868310361240

Hyde, J. S., Bigler, R. S., Joel, D., Tate, C. C., \& van Anders, S. M. (2019). The future of sex and gender in psychology: Five challenges to the gender binary. American Psychologist, 74(2), 171193. https://doi.org/10.1037/amp0000307 
Karpman, B. (1948). Conscience in the psychopath: Another version. American Journal of Orthopsychiatry, 18, 455-491. https://doi. org/10.1111/j.1939-0025.1948.tb05109.x

Keenan, K., \& Shaw, D. (1997). Developmental and social influences on young girls' early problem behavior. Psychological Bulletin, 121(1), 95-113. https://doi.org/10.1037/0033-2909.121.1.95

Kreis, M. K., \& Cooke, D. J. (2011). Capturing the psychopathic female: A prototypicality analysis of the Comprehensive Assessment of Psychopathic Personality (CAPP) across gender. Behavioral Sciences and the Law, 29, 634-648. https://doi.org/10.1002/bsl.1003

Krueger, R. F., Markon, K. E., Patrick, C. J., Benning, S. D., \& Kramer, M. D. (2007). Linking antisocial behavior, substance use, and personality: An integrative quantitative model of the adult externalizing spectrum. Journal of Abnormal Psychology, 116, 645-666. https://doi.org/10.1037/0021-843X.116.4.645

Latzman, R. D., Palumbo, I. M., Sauvigné, K. C., Hecht, L. K., Lilienfeld, S. O., \& Patrick, C. J. (2019). Psychopathy and internalizing psychopathology: A triarchic model perspective. Journal of Personality Disorders, 33, 262-287. https://doi.org/ 10.1521/pedi_2018_32_347

Lenth, R. V. (2021). emmeans: Estimated marginal means, AKA leastsquares means. R package version 1.5.4. https://CRAN.R-project. org/package $=$ emmeans

Letendre, J. (2007). "Sugar and Spice But Not Always Nice": Gender Socialization and its Impact on Development and Maintenance of Aggression in Adolescent Girls. Child and Adolescent Social Work Journal, 24(4), 353-368. https://doi.org/10.1007/ s10560-007-0088-7

Leve, L. D., Kim, H. K., \& Pears, K. C. (2005). Childhood Temperament and Family Environment as Predictors of Internalizing and Externalizing Trajectories From Ages 5 to 17. Journal of Abnormal Child Psychology, 33(5), 505-520. https://doi.org/10.1007/ s10802-005-6734-7

Lilienfeld, S. O., \& Andrews, B. P. (1996). Development and preliminary validation of a self-report measure of psychopathic personality traits in noncriminal population. Journal of Personality Assessment, 66, 488-524. https://doi.org/10.1207/ s15327752jpa6603_3

Lilienfeld, S. O., \& Hess, T. H. (2001). Psychopathic personality traits and somatization: Sex differences and the mediating role of negative emotionality. Journal of Psychopathology and Behavioral Assessment, 23, 11-24. https://doi.org/10.1023/A:1011035306061

Lilienfeld, S. O., Patrick, C. J., Benning, S. D., Berg, J., Sellbom, M., \& Edens, J. F. (2012). The role of fearless dominance in psychopathy: Confusions, clarifications, and fruitful new directions. Personality Disorders, 3, 327-340. https://doi.org/10.1037/a0026987

Lilienfeld, S. O., Watts, A. L., Smith, S. F., \& Latzman, R. D. (2018). Boldness: Conceptual and methodological issues. In C. J. Patrick (Ed.), Handbook of psychopathy (2nd ed., pp. 165-186). Guilford Press.

Lynam, D. R., \& Derefinko, K. J. (2006). Psychopathy and personality. In C. J. Patrick (Ed.), Handbook of psychopathy (pp. 133-155). Guilford Press.

Lynch, S. M., Fritch, A., \& Heath, N. M. (2012). Looking beneath the surface: The nature of incarcerated women's experiences of interpersonal violence, treatment needs, and mental health. Feminist Criminology, 7, 381-400. https://doi.org/10.1177/ 1557085112439224

Marsh, H. W., Morin, A. J. S., Parker, P. D., \& Kaur, G. (2014). Exploratory structural equation modeling: An integration of the best features of exploratory and confirmatory factor analysis. Annual Review of Clinical Psychology, 10, 85-110. https://doi.org/10.1146/annurevclinpsy-032813-153700

McCord, W., \& McCord, J. (1964). The psychopath: An essay on the criminal mind. Van Nostrand.
Miller, J. D., Gaughan, E. T., \& Pryor, L. R. (2008). The Levenson Self-Report Psychopathy Scale: An examination of the personality traits and disorders associated with the LSRP factors. Assessment, 15, 450-464. https://doi.org/10.1177/1073191108316888

Miller, J. D., \& Lynam, D. R. (2012). An examination of the Psychopathic Personality Inventory's nomological network: A metaanalytic review. Personality Disorders: Theory, Research, and Treatment, 3, 305-326. https://doi.org/10.1037/a0024567

Miller, J. D., Watts, A., \& Jones, S. E. (2011). Does psychopathy manifest divergent relations with components of its nomological network depending on gender? Personality and Individual Differences, 50, 564-569. https://doi.org/10.1016/j.paid.2010.11.028

Moffitt, T. E., Caspi, A., Rutter, M., \& Silva, P. A. (2001). Sex differences in antisocial behaviour. Conduct disorder, delinquency, and violence in the Dunedin Longitudinal Study. New York, NY: Cambridge University Press.

Neumann, C. S., Hare, R. D., \& Pardini, D. A. (2015). Antisociality and the construct of psychopathy: Data from across the globe. Journal of Personality, 83, 678-692. https://doi.org/10.1111/jopy.12127

Paiva, T. O., Pasion, R., Patrick, C. J., Moreira, D., Almeida, P. R., \& Barbosa, F. (2020). Further evaluation of the Triarchic Psychopathy Measure: Evidence from community adult and prisoner samples from Portugal. Psychological Assessment, 32(3), e1-e14. https://doi.org/10.1037/pas0000797

Palumbo, I. M., Perkins, E. R., Yancey, J. R., Brislin, S. J., Patrick, C. J., \& Latzman, R. D. (2020). Toward a multimodal measurement model for the neurobehavioral trait of affiliative capacity. Personality Neuroscience, 3. https://doi.org/10.1017/pen.2020.9

Patrick, C. J. (2006). Back to the future: Cleckley as a guide to the next generation of psychopathy research. In C. J. Patrick (Ed.), Handbook of psychopathy (pp. 605-617). Guilford Press.

Patrick, C. J. (2010). Triarchic psychopathy measure (TriPM). (Unpublished manual). https://www.phenxtoolkit.org/index. php?pageLink $=$ browse. protocoldetails \&id $=121601$

Patrick, C. J., Fowles, D. C., \& Krueger, R. F. (2009). Triarchic conceptualization of psychopathy: Developmental origins of disinhibition, boldness, and meanness. Development and Psychopathology, 21, 913-938. https://doi.org/10.1017/S0954579409000492

Patrick, C. J., Joyner, K. J., Watts, A. L., et al. (2021). Latent variable modeling of item-based factor scales: Comment on "Triarchic or septarchic?-Uncovering the Triarchic Psychopathy Measure's (TriPM) Structure," by Roy et al. Personality Disorders: Theory, Research, and Treatment, 12(1), 16-23. https://doi.org/10.1037/ per0000424

Patrick, C. J., Kramer, M. D., Krueger, R. F., \& Markon, K. E. (2013a). Optimizing efficiency of psychopathology assessment through quantitative modeling: Development of a brief form of the Externalizing Spectrum Inventory. Psychological Assessment, 25, 1332-1348. https://doi.org/10.1037/a0034864

Patrick, C. J., Kramer, M. D., Vaidyanathan, U., Benning, S. D., Hicks, B. M., \& Lilienfeld, S. O. (2019). Formulation of a measurement model for the boldness construct of psychopathy. Psychological Assessment, 31, 643-659. https://doi.org/10.1037/pas0000690

Patrick, C. J., Venables, N. C., Yancey, J. R., Nelson, L. D., Hicks, B. M., \& Kramer, M. D. (2013b). A construct-network approach to bridging diagnostic and physiological domains: Application to assessment of externalizing psychopathology. Journal of Abnormal Psychology, 122(3), 902-916. https://doi.org/10.1037/a0032807

Perkins, E. R., Sörman, K., McDermott, K. A., \& Patrick, C. J. (2019). Interrelations among Biologically Relevant Personality Traits, Emotion Regulation Strategies, and Clinical Symptoms. Journal of Psychopathology and Behavioral Assessment, 41, 549-559. https://doi.org/10.1007/s10862-018-9709-z

Pompili, M., Iliceto, P., Lester, D., Innamorati, M., Girardi, P., \& Tatarelli, R. (2009). Manuale italiano del "Beck Hopelessness Inventory.” Firenze, Italy: Organizzazioni Speciali. 
Poy, R., Segarra, P., Esteller, À., López, R., \& Moltó, J. (2014). FFM description of the triarchic conceptualization of psychopathy in men and women. Psychological Assessment, 26, 69-76. https:// doi.org/10.1037/a0034642

Preston, O. C., Watts, A. L., Anestis, J. C., \& Lilienfeld, S. O. (2018). Psychopathic Traits' Differential Relations With Aggression Forms: Considering the Roles of Gender and Gender Role Adherence. Journal of Social and Clinical Psychology, 37(8), 628-658. https://doi.org/10.1521/jscp.2018.37.8.628

R Core Team. (2021). R: A language and environment for statistical computing. Vienna, Austria: R Foundation for Statistical Computing. https://www.R-project.org/

Robbins, P. C., Monahan, J., \& Silver, E. (2003). Mental disorders, violence, and gender. Law and Human Behavior, 27, 561-571. https://doi.org/10.1023/B:LAHU.0000004886.13268.f2

Ruchensky, J. R., Edens, J. F., Corker, K. S., Donnellan, M. B., Witt, E. A., \& Blonigen, D. M. (2018). Evaluating the structure of psychopathic personality traits: A meta-analysis of the Psychopathic Personality Inventory. Psychological Assessment, 30(6), 707-718. https://doi.org/10.1037/pas0000520

Sadeh, N., Javdani, S., Finy, M. S., \& Verona, E. (2011). Gender differences in emotional risk for self- and other-directed violence among externalizing adults. Journal of Consulting and Clinical Psychology, 79, 106-117. https://doi.org/10.1037/a0022197

Salekin, R. T., Rogers, R., \& Sewell, K. W. (1997). Construct validity of psychopathy in a female offender sample: A multitraitmultimethod evaluation. Journal of Abnormal Psychology, 106, 576-585. https://doi.org/10.1037/0021-843X.106.4.576

Schultz, N., Murphy, B., \& Verona, E. (2016). Gender differences in psychopathy links to drug use. Law and Human Behavior, 40, 159-168. https://doi.org/10.1037/lhb0000165

Scott, D. A. I., \& Mikell, T. (2019). 'Gender' and general strain theory: Investigating the impact of gender socialization on young women's criminal outcomes. Journal of Crime and Justice, 42(4), 393-413. https://doi.org/10.1080/0735648X.2018.1559754

Sellbom, M., Donnelly, K. M., Rock, R. C., Phillips, T. R., \& Ben-Porath, Y. S. (2017). Examining gender as moderating the association between psychopathy and substance abuse. Psychology, Crime \& Law, 23, 376-390. https://doi.org/10.1080/1068316X.2016. 1258466

Sellbom, M., Laurinavičius, A., Ustinavičiūtė, L., \& Laurinaitytė, I. (2018). The Triarchic Psychopathy Measure: An examination in a Lithuanian inmate sample. Psychological Assessment, 30(7), e10-e20. https://doi.org/10.1037/pas0000603

Sellbom, M., \& Phillips, T. R. (2013). An examination of the triarchic conceptualization of psychopathy in incarcerated and nonincarcerated samples. Journal of Abnormal Psychology, 122, 208-214. https://doi.org/10.1037/a0029306

Sevecke, K., Lehmkuhl, G., \& Krischer, M. K. (2009). Examining relations between psychopathology and psychopathy dimensions among adolescent female and male offenders. European Child and Adolescent Psychiatry, 18, 85-95. https://doi.org/ 10.1007/s00787-008-0707-7

Sica, C., Drislane, L., Caudek, C., Angrilli, A., Bottesi, G., Cerea, S., \& Ghisi, M. (2015). A test of the construct validity of the Triarchic Psychopathy Measure in an Italian community sample. Personality and Individual Differences, 82, 163-168. https:// doi.org/10.1016/j.paid.2015.03.015

Somma, A., Borroni, S., Drislane, L. E., Patrick, C. J., \& Fossati, A. (2019). Modeling the structure of the triarchic psychopathy measure: Conceptual, empirical, and analytic considerations. Journal of Personality Disorders, 33, 470-496. https://doi.org/ 10.1521/pedi_2018_32_354

Sprague, J., Javdani, S., Sadeh, N., Newman, J. P., \& Verona, E. (2012). Borderline Personality Disorder as a Female
Phenotypic Expression of Psychopathy? Personality Disorders, 3(2), 127-139. https://doi.org/10.1037/a0024134

Stockdale, K. C., Olver, M. E., \& Wong, S. C. P. (2010). The psychopathy checklist: Youth version and adolescent and adult recidivism: Considerations with respect to gender, ethnicity, and age. Psychological Assessment, 22, 768-781. https://doi. org/10.1037/a0020044

Strand, S., \& Belfrage, H. (2005). Gender differences in psychopathy in a Swedish offender sample. Behavioral Sciences \& the Law, 23(6), 837-850. https://doi.org/10.1002/bsl.674

Tull, M. T., Bardeen, J. R., DiLillo, D., Messman-Moore, T., \& Gratz, K. L. (2015). A prospective investigation of emotion dysregulation as a moderator of the relation between posttraumatic stress symptoms and substance use severity. Journal of Anxiety Disorders, 29, 52-60. https://doi.org/10.1016/j.janxdis.2014.11.003

Tuvblad, C., Wang, P., Patrick, C. J., Berntsen, L., Raine, A., \& Baker, L. A. (2019). Genetic and environmental influences on disinhibition, boldness, and meanness as assessed by the triarchic psychopathy measure in 19-20-year-old twins. Psychological Medicine, 49, 1500-1509. https://doi.org/10.1017/ S0033291718002052

Venables, N. C., Hall, J. R., \& Patrick, C. J. (2014). Differentiating psychopathy from antisocial personality disorder: A triarchic model perspective. Psychological Medicine, 44, 1005-1013. https://doi.org/10.1017/S003329171300161X

Verona, E., Hicks, B. M., \& Patrick, C. J. (2005). Psychopathy and suicidality in female offenders: Mediating influences of personality and abuse. Journal of Consulting and Clinical Psychology, 73, 1065-1073. https://doi.org/10.1037/0022-006X. 73.6.1065

Verona, E., Sprague, J., \& Javdani, S. (2012). Gender and factorlevel interactions in psychopathy: Implications for self-directed violence risk and borderline personality disorder symptoms. Personality Disorders: Theory Research and Treatment, 3, 247-262. https://doi.org/10.1037/a0025945

Verona, E., \& Vitale, J. (2018). Psychopathy in women: Assessment, manifestations, and etiology. In C. J. Patrick (Ed.), Handbook of psychopathy (2nd ed., pp. 509-528). Guilford Press.

Verschuere, B., van Ghesel Grothe, S., Waldorp, L., Watts, A. L., Lilienfeld, S. O., Edens, J. F., Skeem, J. L., \& Noordhof, A. (2018). What features of psychopathy might be central? A network analysis of the Psychopathy Checklist-Revised (PCL$\mathrm{R})$ in three large samples. Journal of Abnormal Psychology, 127(1), 51. https://doi.org/10.1037/abn0000315

Viding, E., \& McCrory, E. (2019). Towards understanding atypical social affiliation in psychopathy. The Lancet Psychiatry, 6(5), 437-444. https://doi.org/10.1016/S2215-0366(19)30049-5

Walters, G. D. (2003). Predicting institutional adjustment and recidivism with the Psychopathy Checklist factor scores: A metaanalysis. Law and Human Behavior, 27, 541-558. https://doi. org/10.1023/A:1025490207678

Wilson, D. L., Frick, P. J., \& Clements, C. B. (1999). Gender, somatization, and psychopathic traits in a college sample. Journal of Psychopathology and Behavioral Assessment, 21, 221-235. https://doi.org/10.1023/A:1022825415137

Yancey, J. R., Venables, N. C., \& Patrick, C. J. (2016). Psychoneurometric operationalization of threat sensitivity: Relations with clinical symptom and physiological response criteria. Psychophysiology, 53(3), 393-405. https://doi.org/10.1111/ psyp. 12512

Publisher's Note Springer Nature remains neutral with regard to jurisdictional claims in published maps and institutional affiliations. 